\title{
Differential accumulation of Tau phosphorylated at residues Thr231, Ser262 and Thr205 in hippocampal interneurons and its modulation by Tau mutations (VLW) and amyloid- $\beta$ peptide
}

\author{
Eva Dávila-Bouziguet ${ }^{\mathrm{a}, \mathrm{b}, \mathrm{c}, 1}$, Georgina Targa-Fabra ${ }^{\mathrm{a}, \mathrm{b}, \mathrm{c}, 1}$, Jesús Ávila ${ }^{\mathrm{b}, \mathrm{e}}$, Eduardo Soriano ${ }^{\mathrm{a}, \mathrm{b}, \mathrm{c}, \mathrm{d}}$, \\ Marta Pascual ${ }^{\mathrm{a}, \mathrm{b}, \mathrm{c}, *}$ \\ ${ }^{a}$ Department of Cell Biology, Physiology and Immunology, Institut de Neurociències, Universitat de Barcelona, Barcelona, Spain. \\ ${ }^{\mathrm{b}}$ Centro de Investigación Biomédica en Red sobre Enfermedades Neurodegenerativas (CIBERNED, ISCIII), Spain. \\ ${ }^{\mathrm{c}}$ Vall d'Hebron Institute of Research, Barcelona, Spain. \\ d ICREA Academia, Barcelona, Spain.

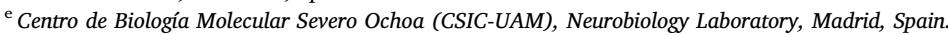

\section{A R T I C L E I N F O}

\section{Keywords:}

Alzheimer's disease

Frontotemporal dementia with parkinsonism

linked to chromosome 17

J20 mice

VLW mice

GABAergic neurons

Tau phosphorylation

\begin{abstract}
A B S T R A C T
Alzheimer's disease (AD) is characterized by the accumulation of amyloid- $\beta$ peptide (A $\beta$ ) and hyperphosphorylated Tau protein (P-Tau). Our recent data showed a differential accumulation of Tau protein phosphorylated at residue Thr231 (pThr231) in distinct hippocampal neurons in VLW mice-a model that overexpresses mutated human Tau. Here we demonstrate that, in VLW mice, the accumulation of human P-Tau in pyramidal cells induces the phosphorylation of murine Tau at residue Thr231 in hippocampal interneurons.

In addition, we show that pSer262 and pThr205 Tau are present specifically in the soma of some hippocampal interneurons in control mice. Analysis of J20 mice-a model that accumulates A $\beta$ - and of VLW animals showed that the density of hippocampal interneurons accumulating pThr205 Tau is lower in VLW mice than in controls. In contrast, the density of interneurons accumulating pThr205 Tau in J20 mice was increased compared to controls in hippocampal regions with a higher A $\beta$ plaque load, thereby suggesting that pThr205 Tau is induced by $A \beta$. No significant differences were found between the density of hippocampal interneurons positive for pSer262 Tau in VLW or J20 mice compared to control animals.

We also show that pSer262 and pThr205 Tau are present in the soma of some hippocampal interneurons containing Parvalbumin, Calbindin or Calretinin in control, VLW, and J20 mice. Moreover, our results reveal that some interneurons in human hippocampi of cases of AD and control cases accumulate pSer262 and pThr205 Tau. Taken together, these data point to a specific role of pSer262 and pThr205 Tau in the soma of hippocampal interneurons in control and pathological conditions.
\end{abstract}

\section{Introduction}

Tau is a microtubule (MT)-associated protein that participates in tubulin cytoskeleton assembly and stabilization (Drubin and Kirschner, 1986; Weingarten et al., 1975), and also in axonal transport regulation and axon development, as well as in other less well-known functions in the synapse (Ittner et al., 2010) and the nucleus (Sultan et al., 2011; Violet et al., 2014). Certain factors can affect the unfolded conformation of Tau and promote its assembly in paired helical filaments (PHFs) (Kidd, 1963), which leads to aggregation in neurofibrillary tangles (NFTs), a feature of several neurodegenerative diseases (Lee et al.,
2001). Together with amyloid- $\beta$ peptide (A $\beta$ ) species and plaques, Tau in NFTs is one of the main histopathological hallmarks of Alzheimer's disease (AD), the most common form of dementia (Ballatore et al., 2007; Bloom, 2014; Haass and Selkoe, 2007).

Mutations can stimulate Tau aggregation, as is the case of familial tauopathies like frontotemporal dementia with parkinsonism linked to chromosome 17 (FTDP-17) (Hutton et al., 1998). In addition, a wide range of post-translational modifications of Tau, notably hyperphosphorylation, can facilitate its aggregation (Kopke et al., 1993). Despite these observations, data show that soluble Tau oligomers, not NFTs, are the most toxic structures for neurons and synapses (Flach et al., 2012;

\footnotetext{
* Corresponding author.

E-mail address: marpascual@ub.edu (M. Pascual).

${ }^{1}$ Co-first author
} 
SantaCruz et al., 2005; Tian et al., 2013; Yoshiyama et al., 2007).

In mature neurons, Tau is found mainly in the axon (Binder et al., 1985) and only small amounts localize to dendrites (Papasozomenos and Binder, 1987). However, the presence of $\mathrm{A} \beta$ oligomers, or Tau hyperphosphorylation, mutations, or overexpression can cause the mislocalization of this protein to the somatodendritic compartment and may even drive it to postsynaptic spines under resting conditions, hence producing excitatory synapse dysfunction (Frandemiche et al., 2014; Götz et al., 1995; Hoover et al., 2010; Thies and Mandelkow, 2007). In this regard, Tau appears to be required for $\mathrm{A} \beta$-induced toxicity, as seen both in vitro (Frandemiche et al., 2014; Jin et al., 2011; Zempel et al., 2013) and in vivo (Ittner et al., 2010; Roberson et al., 2007, 2011). For instance, missorted dendritic Tau mediates the synaptic impairment induced by A $\beta$ (Frandemiche et al., 2014; Ittner et al., 2010; Zempel et al., 2013). In addition, a reduction in endogenous Tau levels in human amyloid precursor protein (APP)-overexpressing mice protects them against synaptic, network, and cognitive deficits (Roberson et al., 2007, 2011).

Tau is a complex protein with more than 85 putative phosphorylation sites (Hanger et al., 2007; Morishima-Kawashima et al., 1995). Certain phosphoepitopes in Tau are recognized by antibodies that are used as diagnostic markers of AD, including pThr205, pThr231 and pSer262 (Goedert et al., 1994; Šimić et al., 2016). Phosphorylation at residue Ser262 in the repeat domain of Tau greatly reduces its affinity for MTs, but also prevents it from assembling into PHFs (Drewes et al., 1995; Schneider et al., 1999; Sengupta et al., 1998). The effect of pThr231 on the affinity of Tau for microtubules is less prominent; primarily, this phosphoepitope in the proline-rich domain of Tau regulates the assembly of tubulin in MTs (Amniai et al., 2009; Cho and Johnson, 2004; Sengupta et al., 1998). In addition, phosphorylation at residues Thr231 and Ser262 may abnormally target Tau to dendritic spines (Xia et al., 2015). Surprisingly, a protective effect against A $\beta$ toxicity has recently been proposed for pThr205 Tau (Ittner et al., 2016). Therefore, the detailed functions of these phosphorylated residues in Tau are still unknown.

Our recent data demonstrate the presence of pThr231 Tau in hippocampal GABAergic interneurons containing Parvalbumin (PV) in VLW animals, a mouse model accumulating P-Tau (Lim et al., 2001; Soler et al., 2017). Our results suggest that a dysfunction in hippocampal interneurons underlies the cognitive deficits associated with tauopathies such as $\mathrm{AD}$ (Soler et al., 2017). In this regard, the dysfunction of GABAergic transmission was recently proposed as one of the key factors in the pathogenesis of network dysfunction in $\mathrm{AD}$ (Busche et al., 2015; Palop and Mucke, 2010), with PV-positive interneurons possibly playing a prominent role. The function of neural circuits depends on the synchronous activity of their components, and deregulation of the excitatory/inhibitory balance seems to contribute to the cortical network alterations and cognitive dysfunction associated with AD (Palop and Mucke, 2016; Verret et al., 2012; Villette and Dutar, 2016).

Here we compared the distribution of several P-Tau forms, namely pThr231, pSer262 and pThr205 Tau, in the hippocampus in normal and pathological conditions in wild-type (WT), and in VLW and J20 mice, which accumulate P-Tau and A $\beta$ respectively (Lim et al., 2001; Mucke et al., 2000), as well as in human samples. The soma of hippocampal interneurons accumulated pSer262 and pThr205 in normal and pathological conditions, thereby suggesting that $A \beta$ induces Tau phosphorylation. These results point to a new role of P-Tau in hippocampal GABAergic interneurons. This neuronal population thus emerges as a new target for therapeutic approaches in $\mathrm{AD}$.

\section{Material and methods}

\subsection{Animals}

To conduct the histological procedures, we used WT adult male mice (C57BL/6J strain; 8-month-old (mo); $n=4$ ) and also $8 \mathrm{mo}$ transgenic adult male mice from two different lines presenting $\mathrm{AD}$ features and with the same genetic background. In this regard, we used VLW mice, which overexpress human Tau protein (hTau) with 4 tubulin-binding repeats and 3 mutations related to FTDP-17: G272V (V), P301L (L) and R406W (W) under the control of the Thy-1 promoter $(n=4)$. The second line was J20 mice, which overexpress the human APP carrying two mutations, namely Swedish (K670N/M671L) and Indiana (V717F) familial AD mutations $(n=4)$.

All animals were kept on a 12-h light-dark schedule with access to food and water ad libitum. All the animal experiments were performed in accordance with the European Community Council Directive and the National Institute of Health guidelines for the care and use of laboratory animals. The local ethical committees also approved these experiments.

\subsection{Human samples}

Human samples from control subjects ( $n=2 ; 61$ and 66 years old) and $\mathrm{AD}$ patients $(n=2 ; 73$ and 91 years old, Braak IV-V) were provided by Dr. Isidre Ferrer, from the Brain Bank of the Institute of Neuropathology at Bellvitge Hospital in Barcelona (for more detailed information see Supplementary Table 1). After the post-mortem interval (PMI) indicated in Supplementary Table 1, the tissue was fixed with $4 \%$ paraformaldehyde (PFA) in $0.1 \mathrm{M}$ phosphate buffer (PB) for $24 \mathrm{~h}$, and then cryoprotected with phosphate-buffered saline (PBS) with $30 \%$ sucrose. It was then frozen by a quick immersion in 2-methylbutane at $-50^{\circ} \mathrm{C}$, and $30 \mu \mathrm{m}$ coronal sections were obtained by cryomicrotomy. Human samples were treated in accordance with the European Community Council Directive and the National Institute of Health guidelines.

\subsection{Immunodetection}

To obtain brain tissue, animals were deeply anesthetized by administrating a lethal dose ( $400 \mu \mathrm{L}$ per $60 \mathrm{~g}$ of weight) of a solution 10:1 of Ketolar $^{\circledast}$ (ketamine hydrochloride $50 \mathrm{mg} / \mathrm{mL}$, Parke-Davis)/ Rompun $^{\circledast}(2 \%$ xylazine-thiazine hydrochloride, Bayer). They were then immediately perfused with 4\% PFA in $0.1 \mathrm{M} \mathrm{PB}$. Next, the brains were post-fixed for $48 \mathrm{~h}$ in $4 \%$ PFA and then cryoprotected with PBS with $30 \%$ sucrose at $4{ }^{\circ} \mathrm{C}$. They were then frozen by a quick immersion in 2 methylbutane at $-50{ }^{\circ} \mathrm{C}$, and $30 \mu \mathrm{m}$ coronal sections were cut. These were stored in a cryoprotectant solution (30\% glycerol, 30\% ethylene glycol, $40 \% 0.1 \mathrm{M} \mathrm{PB}$ ) at $-20^{\circ} \mathrm{C}$ until use.

To detect the accumulation of hTau, pThr231, pSer262 or pThr205 Tau, tissue sections from WT, VLW and J20 mice were blocked for $2 \mathrm{~h}$ and incubated overnight with HT7 mouse anti-hTau (ThermoFisher Scientific; 1/500), AT-180 mouse anti-phosphothreonine 231 (Innogenetics; 1/300), S262 rabbit anti-phosphoserine 262 (Invitrogen $^{\mathrm{TM}}$; 1/100), or T205 rabbit anti-phosphothreonine 205 antibodies (Invitrogen ${ }^{\mathrm{TM}} ; 1 / 1000$ ) at $4^{\circ} \mathrm{C}$. Primary antibodies were visualized by sequential incubation with biotinylated secondary antibodies and $\mathrm{ABC}$ complex ( $2 \mathrm{~h}$ each; Vector Laboratories). The peroxidase reaction was developed with diaminobenzidine (DAB), together with nickel ammonium sulfate, cobalt chloride and $\mathrm{H}_{2} \mathrm{O}_{2}$ to intensify the final signal. The sections were mounted onto gelatinized slides, dehydrated, and coverslipped with Eukitt ${ }^{\circledast}$ (O.Kindler). The same procedure followed for the S262 and T205 antibodies was performed using human samples from control subjects and AD patients.

Some mouse brain sections were also stained with 3D6 mouse antiAPP antibody (obtained from the supernatant of cultured Murine Hybridoma Cell Line, RB96 3D6.32.2.4 (PTA-5130), American Type Culture Collection; 1/200) in order to detect the presence of senile plaques in J20 mice. The primary antibody was visualized by sequential incubation with DAB to produce a brown end product.

To determine whether hippocampal interneurons accumulated PTau, several double fluorescent immunostainings were conducted using 

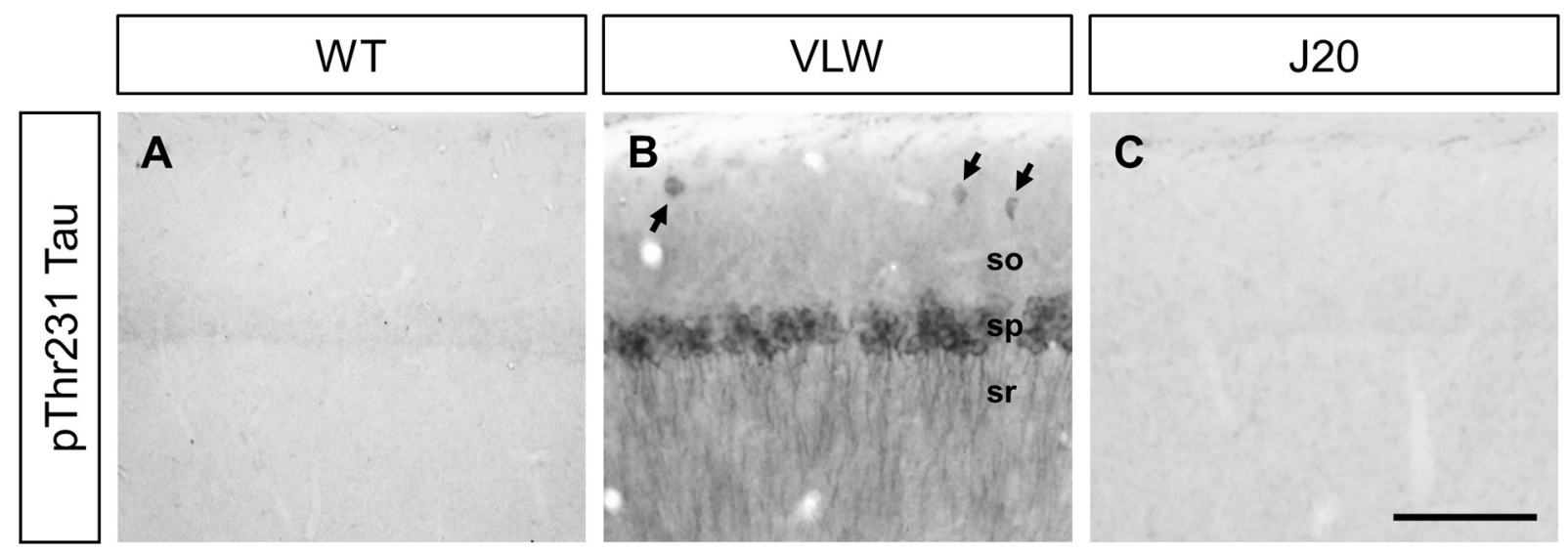

Fig. 1. pThr231 Tau is present in pyramidal neurons and hippocampal interneurons exclusively in VLW mice. Immunodetection of pThr231 Tau-immunopositive cells in hippocampal sections from 8 mo WT, VLW and J20 mice. Tau protein phosphorylated at residue Thr231 detected with AT-180 antibody is not present in WT (A) and J20 (C) hippocampi, whereas VLW mice (B) display pThr231 Tau-positive staining in the sp. and in several hippocampal neurons (arrows). Abbreviations: so, stratum oriens; sp., stratum pyramidale; sr, stratum radiatum. Scale bar: $100 \mu \mathrm{m}$.

S262 or T205 and PV, Calbindin (CB) or Calretinin (CR) primary antibodies. First, brain sections were blocked for $2 \mathrm{~h}$ and incubated overnight simultaneously with goat anti-PV (1/3000), goat anti-CR (1/ 3000 ) or mouse anti-CB (Swant ${ }^{\oplus}$; 1/3000) antibodies and S262 or T205. They were then incubated with Alexa Fluor 568 donkey anti-goat or anti-mouse IgG against interneuron primary antibodies, whereas PTau primary antibodies were targeted with Alexa Fluor 488 donkey anti-rabbit IgG (Invitrogen ${ }^{\mathrm{TM}} ; 1 / 1000$ ), for $2 \mathrm{~h}$. Finally, brain sections were mounted onto slides and coverslipped with Mowiol ${ }^{\circledR}$ (Merck).

To assess P-Tau induction, double fluorescent immunostainings using AT-180 or HT7 antibodies combined with anti-PV antibody were conducted.

Some sections were stained with T205 together with AT-180 antibodies to detect the presence of both P-Tau forms in a single cell.

\subsection{Image acquisition}

Optical microscopy (Nikon E600, Nikon Corporation) observations were focused on the immunohistochemically stained brain sections. Images were acquired through a digital camera (Olympus DP72, Olympus Corporation) coupled to the microscope and were processed by Cell $\mathrm{F}^{\wedge}$ software (Olympus Corporation).

Confocal microscopy (Leica TCS SP5, Leica Microsystems) observations were performed to acquire images from the immunofluorescence-stained samples, using LAS AF software (Leica Microsystems). The images were then processed by Fiji software (Schindelin et al., 2012) to observe possible colocalization between the interneurons and P-Tau markers.

\subsection{Analysis of histological sections}

To estimate the density of interneurons accumulating pSer262 or pThr205 Tau, the samples stained with S262 or T205 antibodies were scanned with a NanoZoomer 2.0HT whole slide imager (Hamamatsu Photonics) at $20 \times$. The density of pSer262 and pThr205 Tau-immunopositive interneurons was quantified in various regions and layers of the hippocampal area (CA1, stratum oriens (so), stratum radiatum (sr), stratum lacunosum moleculare (slm); CA3, so, sr; and DG, stratum moleculare (sm), stratum granulare (sg), hilus) of each section (4 animals/ genotype, 3-4 sections/animal). The cells and area comprising each hippocampal region were quantified using Fiji software. The density of immunopositive hippocampal cells was defined as the density of cells per square millimeter.

To assess the percentage of $A \beta$ plaque load in each hippocampal region, the samples stained with 3D6 antibody were scanned with a
NanoZoomer $2.0 \mathrm{HT}$ whole slide imager at $20 \times$. Later, the Trainable Weka Segmentation plugin from Fiji software was applied to the images by using a set of machine learning algorithms with a collection of image features selected by the user to produce pixel-based segmentations. All images were processed using a macro provided by Sebastién Tosi (Institute for Research in Biomedicine, Barcelona) to identify and quantify the amount of plaque present in a given hippocampal section (4 animals, 4 sections/animal).

\subsection{Statistical analysis of histological data}

Histological data were processed for statistical analysis with GraphPad Prism 6 (GraphPad Software Incorporated). To assess differences between the experimental groups, overall comparisons, namely one-way ANOVA and Kruskal-Wallis tests, were used when the samples fitted a normal distribution or not, respectively. To determine correlation between A $\beta$ plaque load and density of pThr205 Tau-positive cells, the Pearson's $r$ test was used. Significance was set at $p<.05$ : ${ }^{*} p<.05,{ }^{* *} p<.01,{ }^{* * * *} p<.0001$. Statistical values are presented as mean \pm standard error of the mean (SEM).

\section{Results}

\subsection{Tau phosphorylated at residue Thr231 is present in the soma of} hippocampal interneurons specifically in VLW mice

To analyze the pattern of Tau phosphorylation in the hippocampus in control and pathological conditions, we first performed immunodetection of pThr231 Tau on hippocampal sections from 8 mo WT mice, VLW mice, which accumulate hyperphosphorylated forms of Tau, and J20 animals, which accumulate A $\beta$. As previously described (Lim et al., 2001; Soler et al., 2017), VLW mice showed intense immunostaining in the soma and apical dendrites of pyramidal neurons in CA1-3. In addition, as we previously described (Soler et al., 2017), the soma of some hippocampal interneurons located mainly in the so also accumulated pThr231 Tau (Fig. 1B). In contrast, WT and J20 mice did not show pThr231-positive cells in any region of the hippocampus (Fig. 1A, C). These data suggest that the overexpression of mutated hTau in VLW mice has a direct effect on the accumulation of pThr231 Tau in hippocampal interneurons, absent in control mice and in J20 animals. 

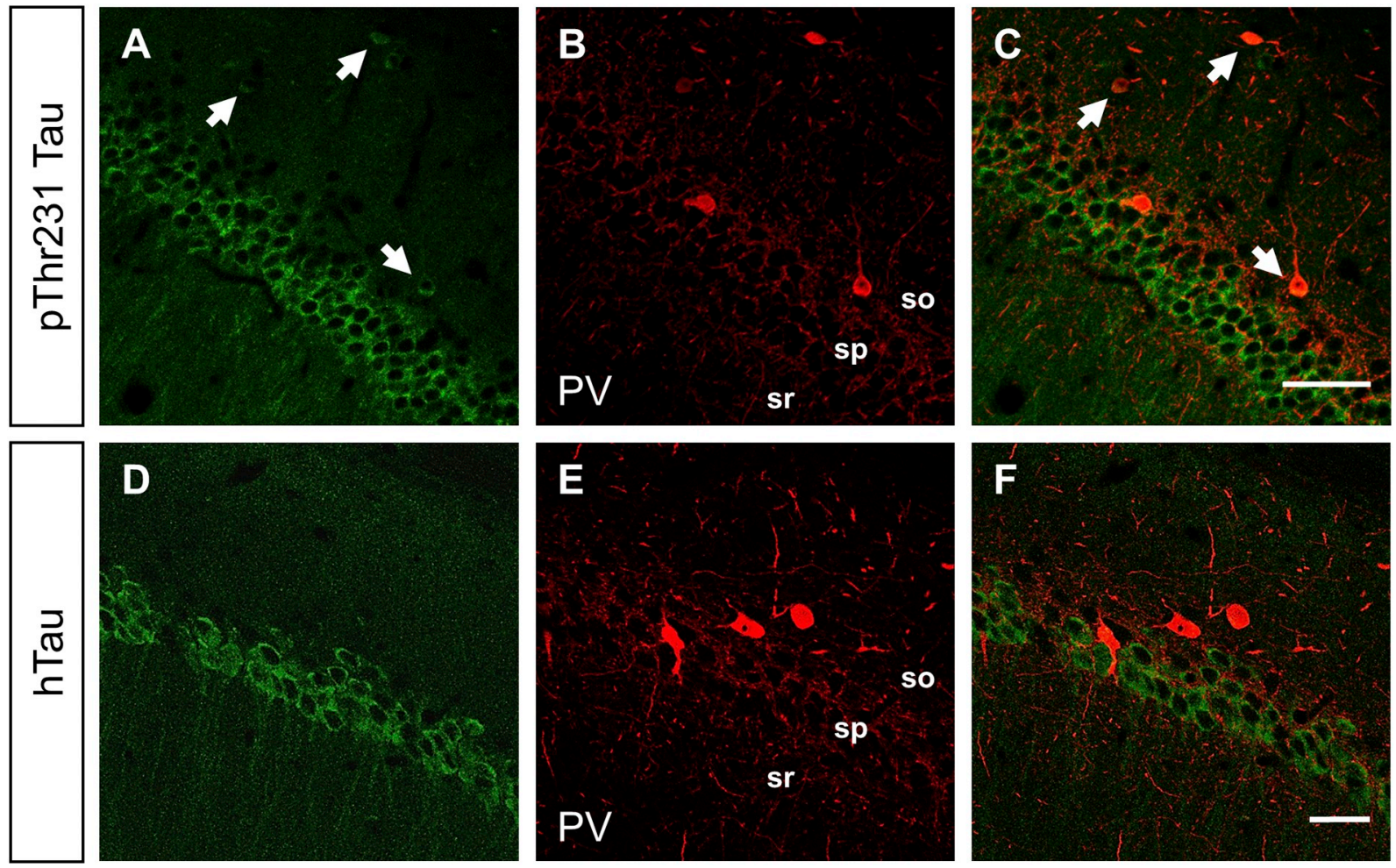

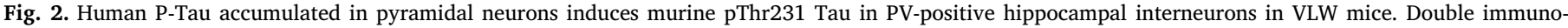

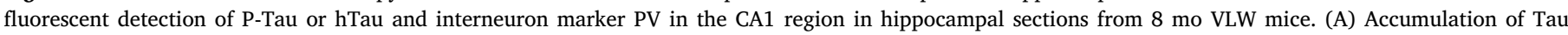

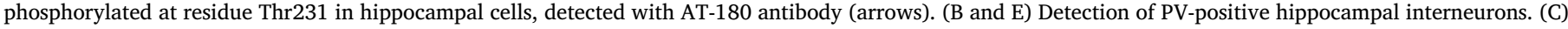

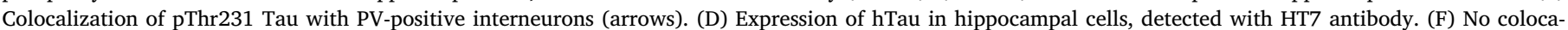

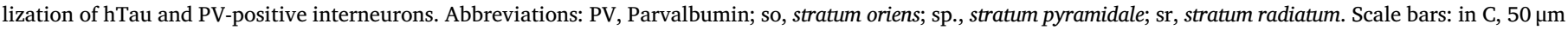
(applies to A-C); in F, $25 \mu \mathrm{m}$ (applies to D-F).

\subsection{Accumulation of pThr231 hTau in pyramidal cells induces $p$ Thr231 murine Tau in PV-positive hippocampal interneurons in VLW mice}

VLW mice overexpress mutated hTau under the Thy- 1 promoter, which leads to the accumulation of P-Tau mainly in pyramidal neurons in the hippocampus (Lim et al., 2001). Moreover, we previously demonstrated an accumulation of pThr231 Tau in PV-positive hippocampal interneurons in VLW mice (Soler et al., 2017).

To determine whether the presence pThr231 Tau in hippocampal interneurons in VLW mice is due to an overexpression of mutated hTau in these cells or to intercellular P-Tau induction, we first detected specifically hTau by the use of HT7 antibody in WT, VLW and J20 hippocampi. Our data confirmed that WT and J20 mice did not accumulate hTau (Supplementary Fig. 1A-B, E-F), and indicated that only pyramidal neurons in CA1-3 expressed hTau in VLW animals (Supplementary Fig. 1C, D). No signal was observed in neurons outside the pyramidal cell layer, indicating that hippocampal interneurons did not express hTau in VLW mice. In order to confirm this observation, we performed double fluorescent immunodetection on hippocampal sections from 8 mo VLW mice. Using an anti-PV antibody to detect hippocampal interneurons combined with anti-pThr231 Tau or with HT7, which specifically detects hTau, we found that PV-positive interneurons accumulated pThr231 Tau but not hTau (Fig. 2A-F). These observations indicate that the accumulation of mutated hTau in pyramidal neurons induces the phosphorylation of endogenous Tau at residue Thr231 in PV-positive interneurons in VLW mice, thereby demonstrating an intercellular spread of P-Tau in vivo.
3.3. Hippocampal interneurons accumulate P-Tau at residues Ser262 and Thr205 in their soma in non-pathological conditions

Tau hyperphosphorylation is associated with $\mathrm{AD}$ and other neurodegenerative conditions (Iqbal et al., 2016; Khan and Bloom, 2016); however, the physiological functions of Tau are also regulated by phosphorylation. In fact, Tau phosphorylation at different sites could have different outcomes for each Tau function (Avila, 2009; Medina et al., 2016). Some phosphorylated Tau residues are related to neurodegenerative processes in humans, but their importance in non-pathological conditions is not clear. To analyze the phosphorylation of Tau in physiological conditions, we performed immunohistochemistry against pSer262 and pThr205 Tau on hippocampal sections from 8 mo WT mice. Our results revealed that some hippocampal neurons located in the so and sr of CA1-3 (Fig. 3A, B) and also scattered in the sg and in the hilus of the dentate gyrus (DG, Fig. 3C) showed pSer262 Tau-immunopositive staining in their soma. In addition, some pThr205 Taupositive cells were also present in the so and sr of CA1-3, and dispersed in the sg, sm and in the hilus of the DG (Fig. 3D-F). The distribution and morphology of these cells appeared to correspond to hippocampal interneurons. Using double immunodetection of pSer262 and pThr205 Tau with hippocampal GABAergic neuron markers such as PV, CB and CR, we show that the pSer262 and pThr205 Tau-positive cells correspond to GABAergic hippocampal cells containing PV, CB and CR (Fig. 4A-I). We quantified the presence of P-Tau forms in PV-immunopositive cells, the main population of GABAergic hippocampal cells. In the PV-positive cell population, $62 \%$ of the cells accumulated pSer262 Tau and 58\% of them presented pThr205 Tau. These data demonstrate that pSer262 and pThr205 Tau accumulate in the soma of hippocampal interneurons in non-pathological conditions. 


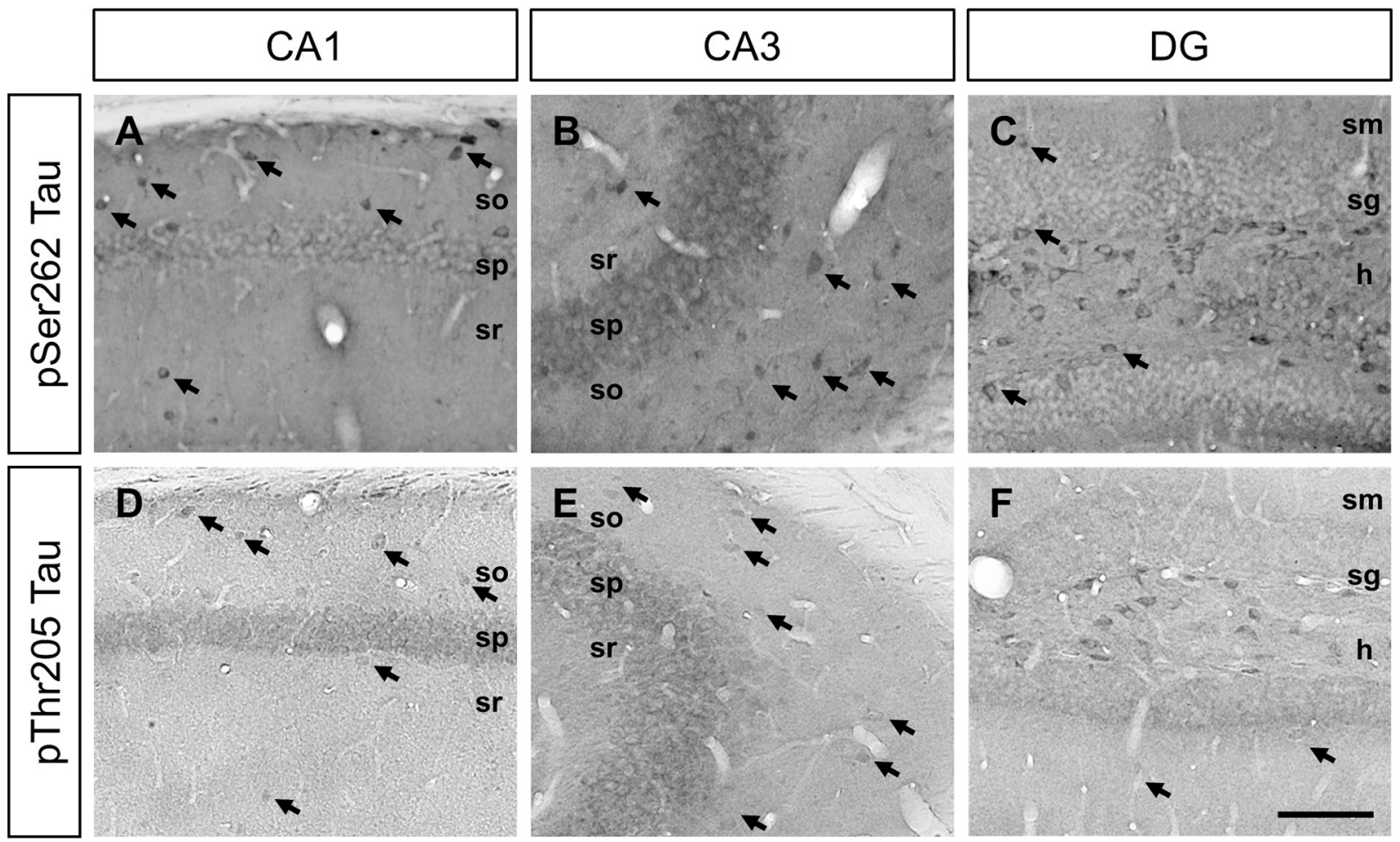

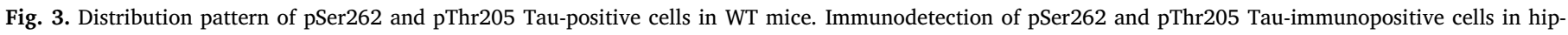

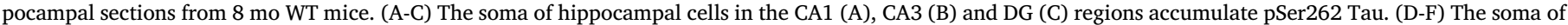

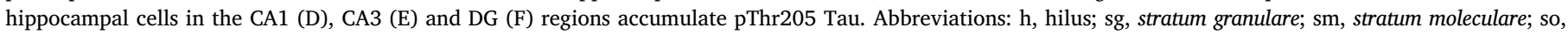
stratum oriens; sp., stratum pyramidale; sr, stratum radiatum. Scale bar: $100 \mu \mathrm{m}$.

\subsection{The distribution and density of pSer262 Tau-positive hippocampal interneurons are similar in WT, VLW and J20 mice}

To study whether pSer262 Tau accumulation in the soma of hippocampal interneurons is also present in pathological conditions, we next compared pSer262 Tau immunodetection on hippocampal sections from WT animals with those of VLW and J20 mice. Like the hippocampi of WT animals, those of VLW and J20 mice showed some scattered neurons in the so and sr of CA1-3 (Fig. 5B-C, F-G), and in the hilus, sg and sm of the DG (Fig. 5J-K). Therefore, we studied the density of pSer262 Tau-positive cells by comparing WT mice with VLW and J20 animals. No differences in the density of interneurons accumulating pSer262 Tau in the hippocampus were detected between the three animal models. Neither were differences observed when CA1, CA3 and the DG were analyzed separately (Fig. 5D, H, L).

Thus, our data show that there are no differences in the distribution pattern of pSer262 Tau or in the density of cells accumulating this PTau form in the hippocampus between normal and pathological conditions. These results indicate that pSer262 accumulation in the soma of hippocampal interneurons is independent of the $\mathrm{A} \beta$ or P-Tau present in the hippocampus.

\subsection{The density of pThr205 Tau-immunopositive hippocampal interneurons decreases in VLW mice}

Next, we compared pThr205 Tau accumulation in the hippocampus of VLW and WT mice. In contrast to data on pSer262 Tau, differences were detected in the distribution of pThr205 Tau-positive cells between the normal and the pathological models. In this regard, there was a clear accumulation of pThr205 Tau in VLW pyramidal cells while this was not observed in WT animals (Fig. 6A, B). VLW mice overexpress mutated hTau mostly in these cells, thus accumulating P-Tau in the pyramidal layer (Lim et al., 2001; Soler et al., 2017).

In addition to pyramidal cells, some mossy cells and several interneurons, mainly in the so and sr, accumulated pThr205 Tau in the hippocampus of VLW mice (Fig. 6A-B, E-F, I-J). We then analyzed the number of pThr205 Tau-positive cells in distinct hippocampal regions. The density of pThr205 Tau-positive cells in VLW mice was lower than in age-matched WT mice, mainly in CA1 and CA3 regions ( $45 \%$ and $47 \%$ of reduction respectively, Fig. $6 \mathrm{D}, \mathrm{H}, \mathrm{L}$ ). Nevertheless, regarding the density of pThr205 Tau-positive cells in the DG, no differences were found between the WT and VLW mice (Fig. 6L; $112.5 \pm 12.6$ and $87.6 \pm 9.4$, respectively).

Our previous data (Soler et al., 2017) demonstrated that some PVpositive interneurons, the most abundant subtype of hippocampal interneurons (Freund and Buzsaki, 1996; Matyas et al., 2004), accumulated pThr231 Tau in VLW mice (Soler et al., 2017). It has been described that Tau phosphorylation at specific residues depends on phosphorylation at other Tau epitopes (Ando et al., 2016). We therefore examined whether the decrease in Thr205 Tau phosphorylation in VLW mouse interneurons was due to the presence of pThr231 Tau in PVpositive interneurons. By means of double immunodetection using the AT-180 antibody against pThr231, and the T205 antibody against pThr205 (Fig. 7), we demonstrated colocalization between T205 and AT-180 staining in some hippocampal interneurons located mainly in the so, but also in pyramidal neurons (Fig. 7A-C). Therefore, some neurons in VLW mice accumulated pThr231 and pThr205 Tau simultaneously. This observation thus suggests that pThr231 Tau does not repress the phosphorylation of Tau at residue Thr205.

\subsection{The density of pThr205 Tau-immunopositive hippocampal interneurons increases in the presence of $A \beta$ accumulation in J20 animals}

Analysis of the hippocampi of J20 mice subsequently demonstrated the presence of intensely immunostained pThr205 Tau-positive cells in the so and sr of the CA1-3 and in the hilus and sm of the DG (Fig. 6C, G, $\mathrm{K})$. Comparison of the number of pThr205 Tau-positive interneurons in J20 and WT animals showed an almost 1.5-fold increase in the density 



Fig. 4. WT mice accumulate pSer262 and pThr205 Tau in PV-, CR- and CB-positive hippocampal interneurons. Double immunofluorescent detection of pSer262 or pThr205 Tau and interneuron markers PV, CR and CB in hippocampal sections from 8 mo WT mice. (A-F) PV-, CR- and CB-positive hippocampal interneurons (red) accumulate Tau phosphorylated at residue Thr205 (green) in 8 mo WT mice. Colocalization of pThr205 Tau with PV- (arrows in C) and CR-positive (arrows in F) interneurons. (G-I) PV-, CR- and CB-positive hippocampal interneurons (red) accumulate Tau phosphorylated at residue Ser262 (green) in 8 mo WT mice. Colocalization of pSer262 Tau with CB-positive (arrows in I) interneurons. Abbreviations: CB, Calbindin; CR, Calretinin; PV, Parvalbumin; so, stratum oriens; sp., stratum pyramidale; sr, stratum radiatum. Scale bar: $50 \mu \mathrm{m}$. (For interpretation of the references to colour in this figure legend, the reader is referred to the web version of this article.)

of these cells in the so of the CA1 (Fig. 6D; WT: $263.7 \pm 7.6$ and J20: $393.7 \pm 39.3 ; p=.0104$ ) and a 2 -fold increase in the DG (Fig. 6L; WT: $112.5 \pm 12.6$ and $\mathrm{J} 20: 224.5 \pm 35.0 ; p=.0203)$ of $\mathrm{J} 20$ mice. No differences were found in the sr $+\mathrm{slm}$ of the CA1 or in the CA3 when compared with WT data (Fig. 6D, H). Furthermore, neither were differences in the density of pThr205 Tau-positive cells detected in the hilus (WT: $606.5 \pm 77.1$ and J20: $833.8 \pm 139.1 ; p=.194$ ). Given that mossy cells are the most abundant population in this region, the differences observed in the DG appear to correspond mainly to an increase in the density of pThr205 Tau-positive interneurons.

A number of studies have demonstrated how $A \beta$ influences Tau hyperphosphorylation (Forner et al., 2017; Götz et al., 2001; Ittner and Götz, 2011). Given that the increase in the density of pThr205 Taupositive cells in J20 mice with respect to WT animals was not homogeneous in all hippocampal regions (Fig. 6D, L), the percentage of increase was calculated in CA1, CA3 and DG independently. Considering that the so showed statistical differences only in the CA1 (Fig. 6D), the distinct strata of this region were studied separately. Comparison of J20 mice with control animals revealed that the CA1 so $(33.0 \pm 1.9 \%)$ and the DG $(45.4 \pm 5.6 \%)$ displayed the highest percentage of increase in the density of pThr205 Tau-positive cells, while the CA1 sr, together with the CA1 slm (sr + slm) and the CA3, showed only a slight increase $(7.1 \pm 3.1 \%$ and $5.5 \pm 3.9 \%$, respectively). Statistical analysis showed a significant increase in the so of the CA1 and in the DG compared with the sr + slm of the CA1 and with the CA3 (Fig. 8A). These data indicate a differential increase in the density of pThr205 Tau-positive cells in distinct hippocampal regions.

To determine whether these specific increases in the DG and so of 

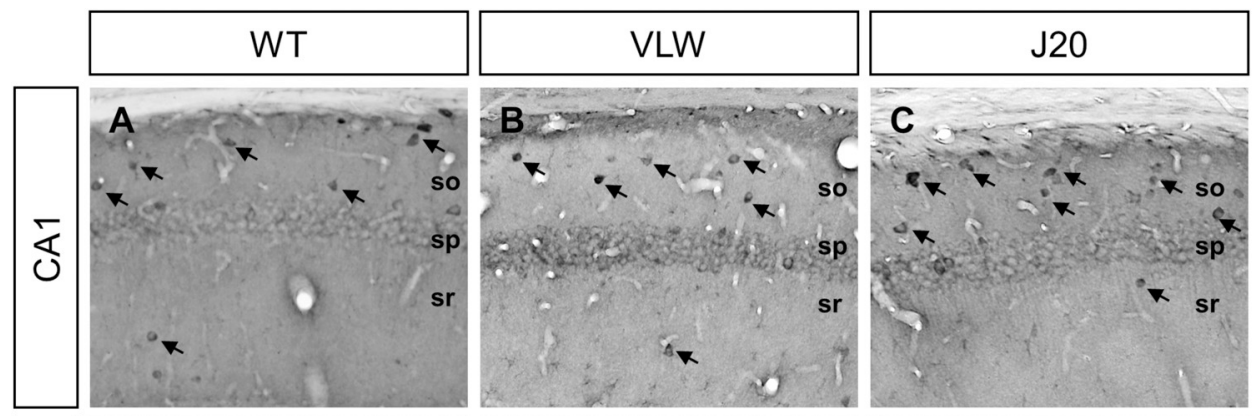

pSer262 Tau-positive cells $/ \mathrm{mm}^{2}$
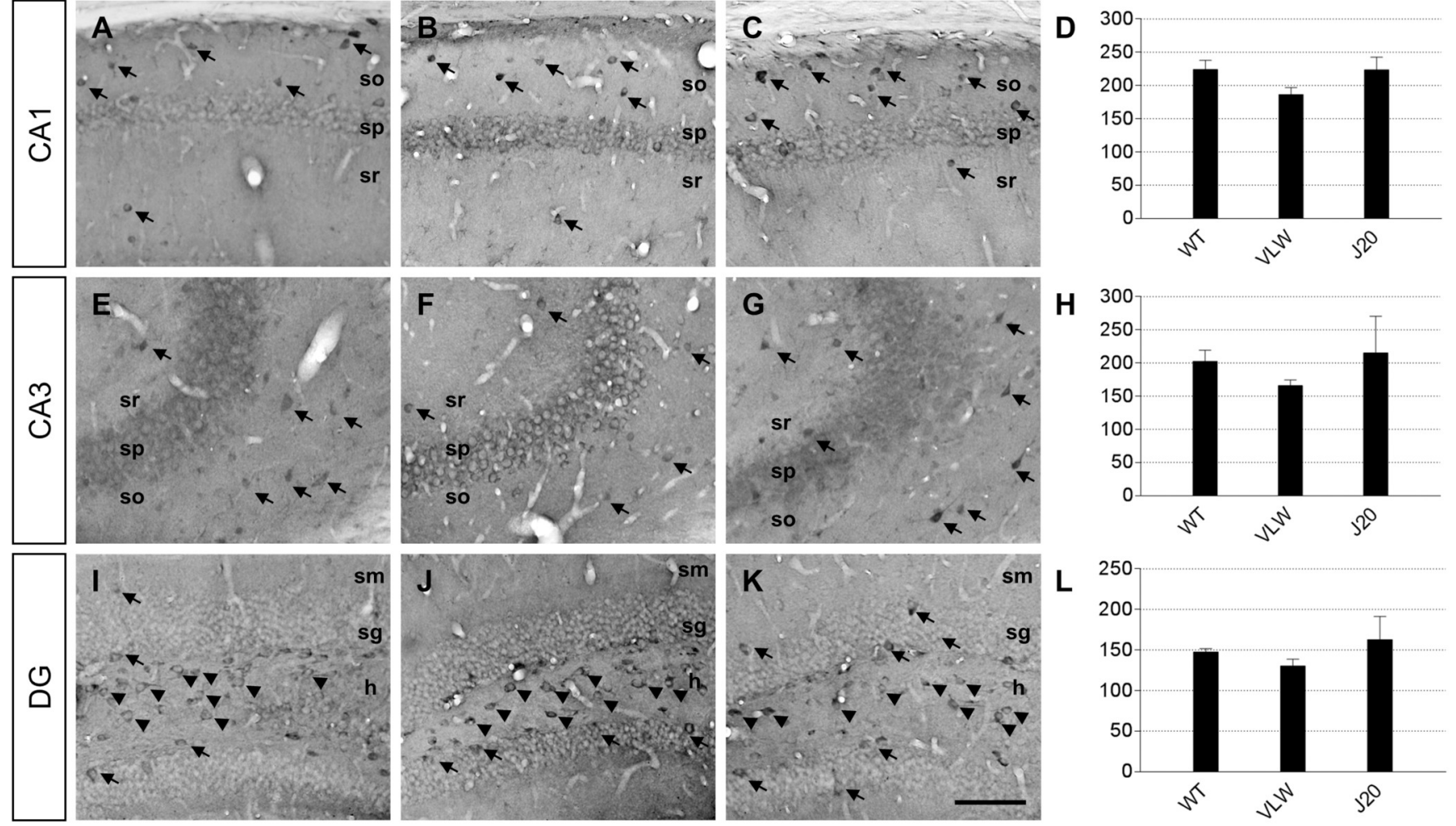

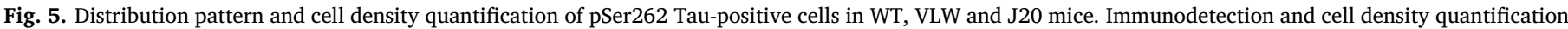

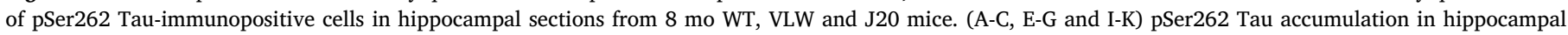

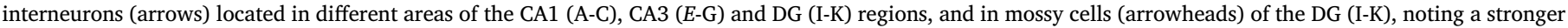

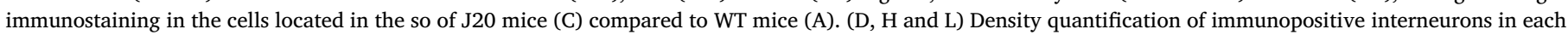

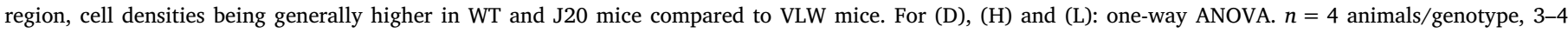

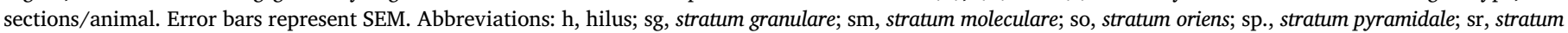
radiatum. Scale bar: $100 \mu \mathrm{m}$.

the $\mathrm{CA} 1$ region correlate with the presence of $\mathrm{A} \beta$ plaques, we performed 3D6 immunostaining. As previously described (Furcila et al., 2018), A $\beta$ plaques accumulated in the CA1 and DG regions (Fig. 8C), accounting for $35 \%$ and $47 \%$ of the $A \beta$ in the hippocampus (Fig. $8 B$ ). Our results showed a high degree of correlation between the increase in pThr205 Tau-positive cells and the presence of $\mathrm{A} \beta$ plaques (Fig. 8D).

Taken together, these results demonstrate that the regions that showed an increase in cells accumulating pThr205 Tau correlated with those with a higher $A \beta$ plaque load, thereby pointing to an inductive effect of $A \beta$ in the phosphorylation of Tau at residue Thr205.

\subsection{The soma of $P V$-, $C R$ - and $C B$-positive hippocampal interneurons accumulate pSer262 and pThr205 Tau in VLW and J20 mice}

Our data established that pSer262 and pThr205 Tau were present in the soma of some neurons scattered throughout the hippocampus in normal and pathological conditions. To identify the hippocampal interneuron populations that accumulated both P-Tau forms, we performed a double immunodetection using PV, CB or CR interneuron markers and S262 or T205 antibodies in brain sections from VLW and J20 mice. Our results revealed colocalization between the hippocampal interneuron markers PV, CR and CB and the S262 (Fig. 9D-F, G-I) or T205 (Fig. 9A-C, J-L) antibody signal.

These findings therefore indicate that both pSer262 and pThr205 Tau accumulate in hippocampal PV-, CR- and CB-positive interneurons in VLW and J20 mice, as previously observed in WT animals.

\section{8. pSer262 and pThr205 Tau accumulate in human hippocampal interneurons in normal and pathological conditions}

Our data demonstrated the presence of pSer262 and pThr205 Tau in the soma of hippocampal interneurons in both WT animals and pathological mouse models of $\mathrm{AD}$. We therefore addressed whether human hippocampal interneurons also accumulate pSer262 Tau and pThr205 Tau. To this end, we analyzed human hippocampal sections from two control subjects and from two AD patients (Braak IV-V). Using immunohistochemistry against pSer262 and pThr205 Tau, we demonstrated that several human hippocampal neurons showed an immunopositive signal for pSer262 (Fig. 10A, B) or pThr205 Tau (Fig. 10C, D) in normal and pathological conditions. The pSer262 and pThr205 Tau-positive cells were large multipolar neurons located outside the pyramidal and granular cell layers, mainly in the sr and so. The location and morphological characteristics of cells accumulating pSer262 or pThr205 Tau seemed to correspond to interneurons. Although the staining in hippocampal interneurons differed from the NFTs observed in pyramidal neurons in AD samples, these P-Tau forms had different cellular distributions. The pSer262 Tau staining was spread evenly within the entire neuron and was higher in $\mathrm{AD}$ samples. In contrast, the pThr205 Tau staining was homogeneously distributed, but it also formed somatic clusters both in control and AD samples.

On the basis of our findings, we conclude that pSer262 and pThr205 Tau accumulate in hippocampal interneurons in mice and human subjects in normal and pathological conditions. 

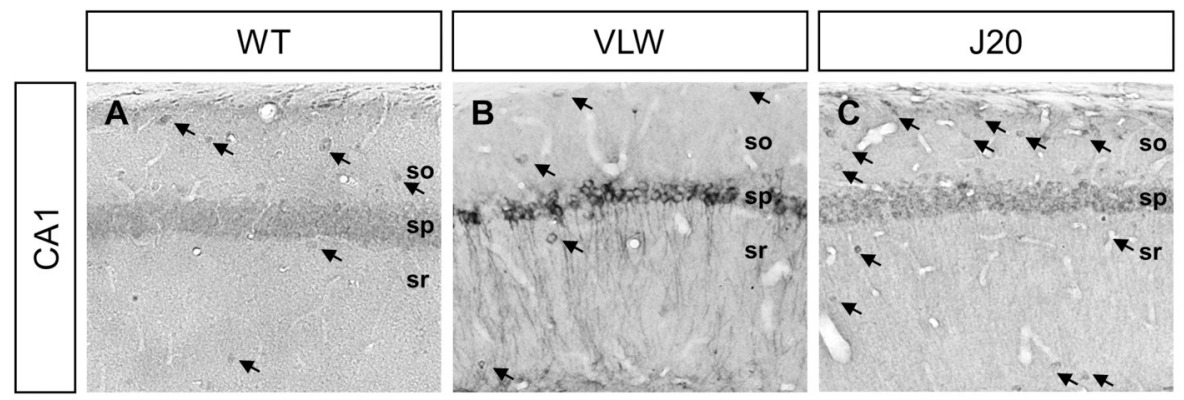

pThr205 Tau-positive cells $/ \mathrm{mm}^{2}$
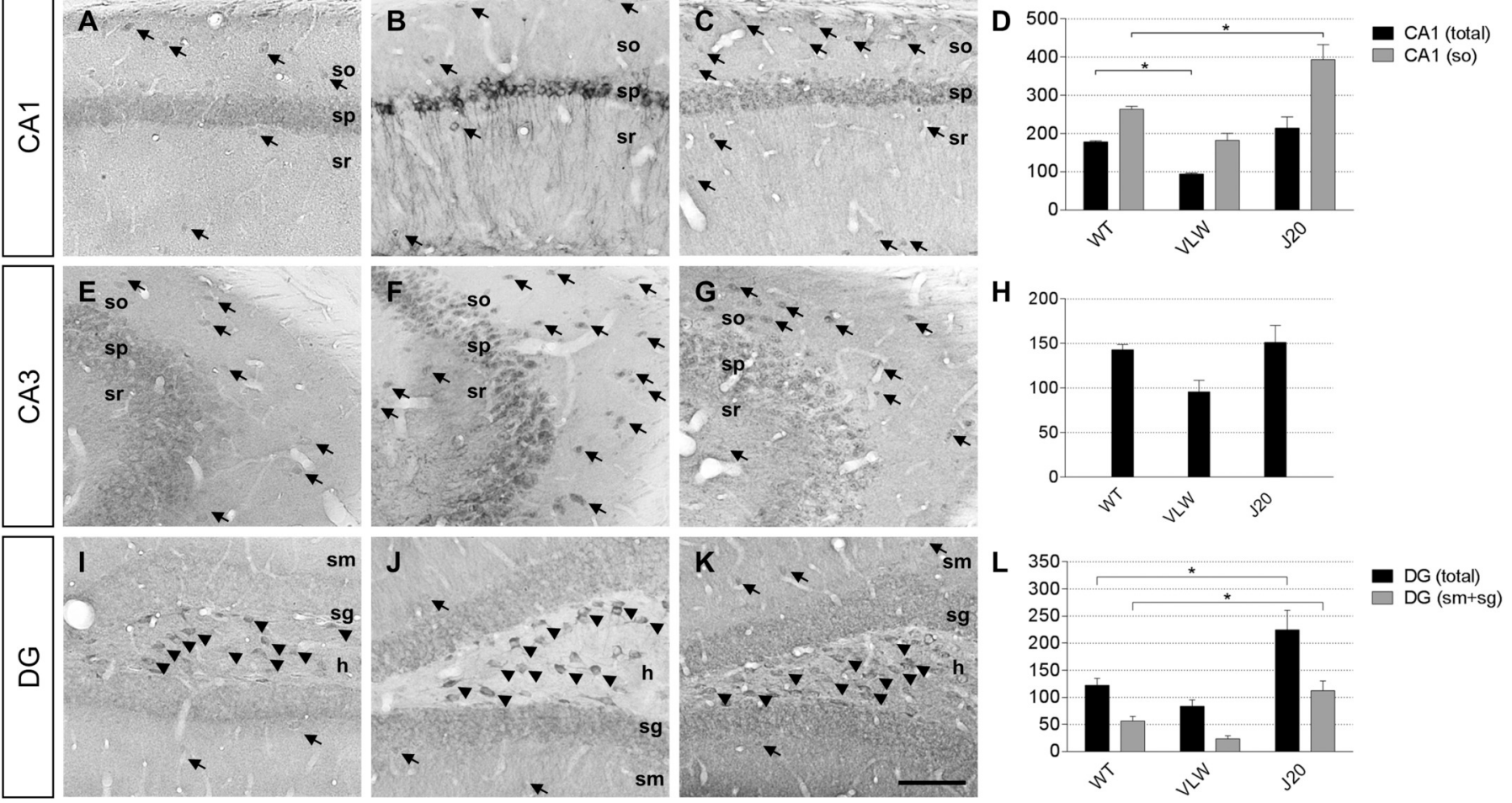

Fig. 6. Distribution pattern and cell density quantification of pThr205 Tau-positive cells in WT, VLW and J20 mice. Immunodetection and cell density quantification of pThr205 Tau-immunopositive cells in hippocampal sections from 8 mo WT, VLW and J20 mice. (A-C, E-G and I-K) pThr205 Tau accumulation in hippocampal interneurons (arrows) located in different areas of the CA1 (A-C), CA3 (E-G) and DG (I-K) regions, and in mossy cells (arrowheads) of the DG (I-K), noting a stronger immunostaining in the sp of VLW mice (B) compared to WT mice (A). (D, H and L) Density quantification of immunopositive interneurons in each region, cell densities being generally higher in WT and J20 mice compared to VLW mice. For (D), (H) and (L): one-way ANOVA, * $p<.05$. $n=4$ animals/genotype, 3-4 sections/animal. Error bars represent SEM. Abbreviations: h, hilus; sg, stratum granulare; sm, stratum moleculare; so, stratum oriens; sp., stratum pyramidale; sr, stratum radiatum. Scale bar: $100 \mu \mathrm{m}$.

\section{Discussion}

4.1. pThr231 hTau in pyramidal cells induces $p$ Thr231 murine Tau in PVpositive hippocampal interneurons specifically in VLW mice

Our previous studies (Soler et al., 2017) demonstrated that hippocampal neuron populations accumulate distinct forms of P-Tau in VLW mice, an animal model that overexpresses mutated hTau. This model shows an accumulation of pThr231 Tau in pyramidal cells, mossy cells and PV-positive interneurons. Our present data indicate that only pyramidal neurons in VLW mice express hTau; in addition, we show that the pThr231 Tau-positive signal is absent in WT hippocampi, thereby suggesting a specific effect of P-Tau accumulation on the phosphorylation of Tau in hippocampal interneurons.

P-Tau aggregates spread and replicate in a prion-like manner. It has been shown, mainly in cell culture experiments, that the uptake of pathological Tau seeds causes hyperphosphorylation, misfolding and aggregation of monomeric Tau in recipient cells (Clavaguera et al.,
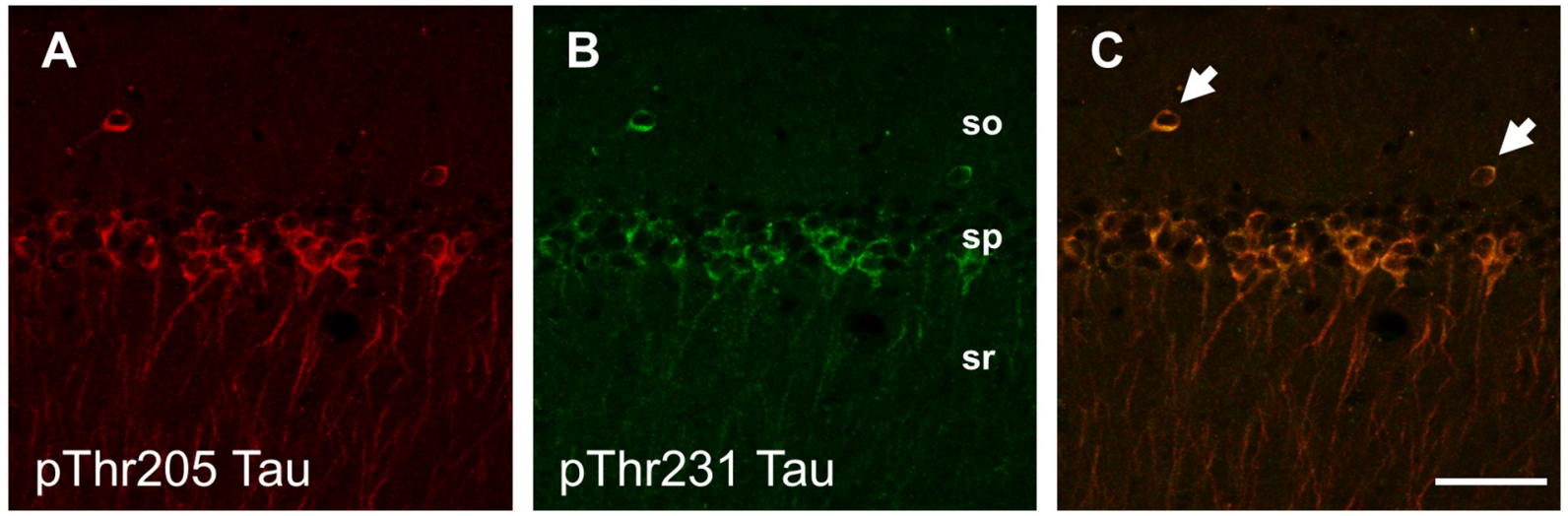

Fig. 7. Hippocampal interneurons and pyramidal cells accumulate both pThr231 and pThr205 Tau in 8 mo VLW mice. Double immunofluorescent detection of pThr231 and pThr205 Tau in 8 mo VLW mice showed hippocampal interneurons located in the stratum oriens (so) and pyramidal neurons accumulating Tau phosphorylated at residue Thr205 (red, A) and pThr231 (green, B). Colocalization of pThr205 with pThr231 Tau (arrows in C) in hippocampal interneurons. Scale bar: $50 \mu \mathrm{m}$. (For interpretation of the references to colour in this figure legend, the reader is referred to the web version of this article.) 


\section{A \% increase in pThr205 Tau-positive cell density in J20 mice}
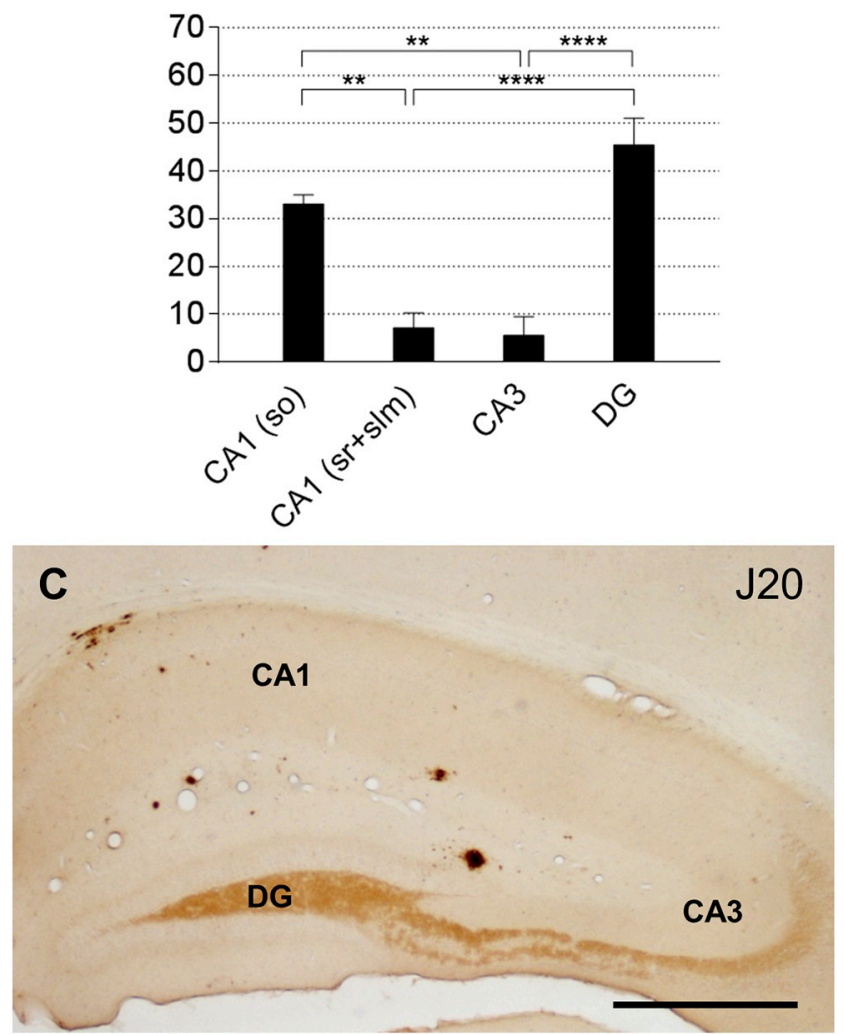

B

\section{$\%$ of $A \beta$ plaques}

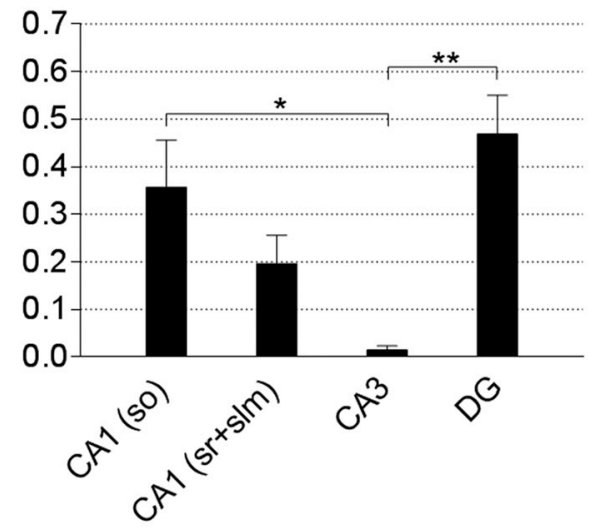

D

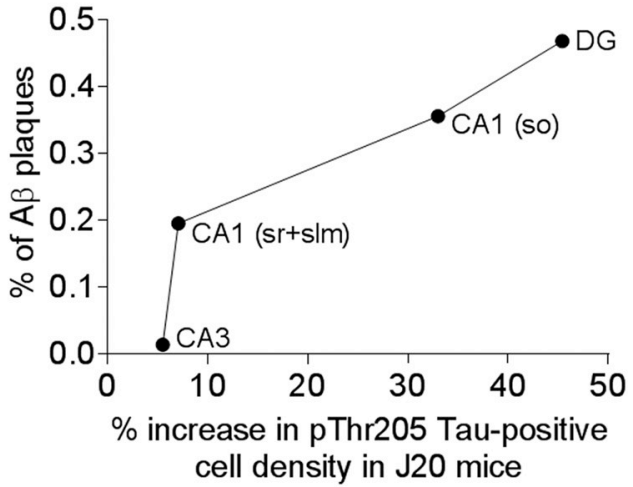

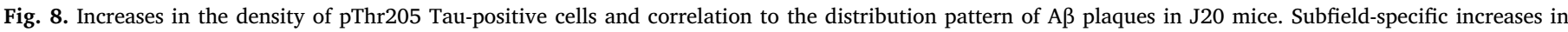

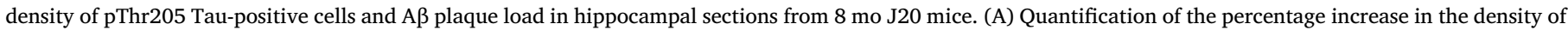

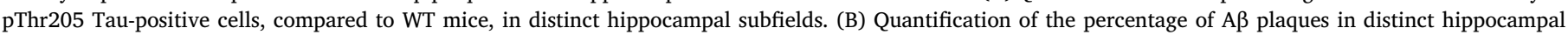

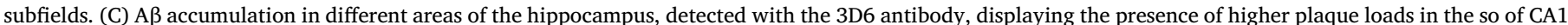

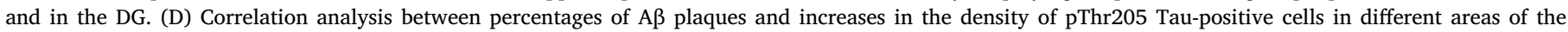

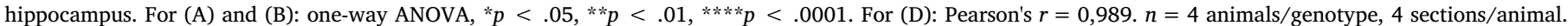
Error bars represent SEM. Abbreviations: slm, stratum lacunosum moleculare; so, stratum oriens; sr, stratum radiatum. Scale bar: $500 \mu \mathrm{m}$.

2009; Polanco et al., 2016; Wang et al., 2017). Here we describe in vivo that overexpression of mutated hTau in pyramidal neurons induces the phosphorylation of murine Tau at residue Thr231 in PV-positive hippocampal interneurons.

\subsection{Hippocampal interneurons and mossy cells accumulate pSer262 Tau in} control and pathological conditions

Our results show that pSer262 Tau accumulates in the soma of PV-, CR- and CB-positive interneurons and mossy cells in WT, VLW and J20 mice. Nevertheless, Tau is normally located in the axon, although lower levels are also present in the somatodendritic compartment and nucleus (Avila et al., 2004; Hernández and Avila, 2007). Many studies have reported the development of non-typical functions of Tau protein alongside the dendritic spines or even in the nucleus. These functions include maintenance of the integrity of genomic DNA, and cytoplasmic and nuclear RNA, as well as the regulation of NMDA receptors and synaptic plasticity (Guo et al., 2017; Sotiropoulos et al., 2017).

In addition, pSer262 Tau has been described as pathological and used as a diagnostic marker for AD (Braak et al., 2011; Šimić et al., 2016; Wang and Mandelkow, 2016). Several studies have reported the capacity of $\mathrm{A} \beta$ to induce Tau hyperphosphorylation (Bolmont et al., 2007; Götz et al., 2001; Stancu et al., 2014), as well as the relevance of the same P-Tau forms in promoting the same effect on other Tau molecules, hence increasing the P-Tau burden (Šimić et al., 2016). Given that our data suggest that the phosphorylation of residue Ser262 is not influenced by the presence of hyperphosphorylated forms of Tau in VLW animals or by the accumulation of A $\beta$ in J20 mice, it would appear that pSer262 Tau in the soma of hippocampal interneurons and mossy cells has a specific function that is independent of AD pathology.

On the basis of our results, we propose that Tau shows distinct patterns of phosphorylation in hippocampal interneurons and mossy cells, possibly in order to exert functions other than those performed exclusively in the axon. Our data reinforce the notion that, despite being considered pathological (Guo et al., 2017), pSer262 Tau is not induced by the accumulation of P-Tau or A $\beta$.

\subsection{The presence of P-Tau and A $\beta$ influences the accumulation of pThr205 Tau in hippocampal interneurons}

Our results show that the soma of PV-, CR- and CB-positive interneurons and mossy cells accumulate pThr205 Tau in WT, VLW and J20 mice. These data point to a physiological role of pThr205 Tau in the somatic region of hippocampal interneurons and mossy cells. In addition, our findings reveal a significant decrease in the density of pThr205 Tau-positive cells in the CA1 and CA3 regions of VLW mice. As previously described, pThr231 Tau accumulates only in PV-positive cells in the hippocampal interneuron population (Soler et al., 2017). Likewise, other studies have stated that the phosphorylation of specific residues may influence-by inducing or repressing-phosphorylation in other regions or domains of Tau (Ando et al., 2016). Our results reveal that pThr231 and pThr205 Tau coexist in a single cell, thereby suggesting 

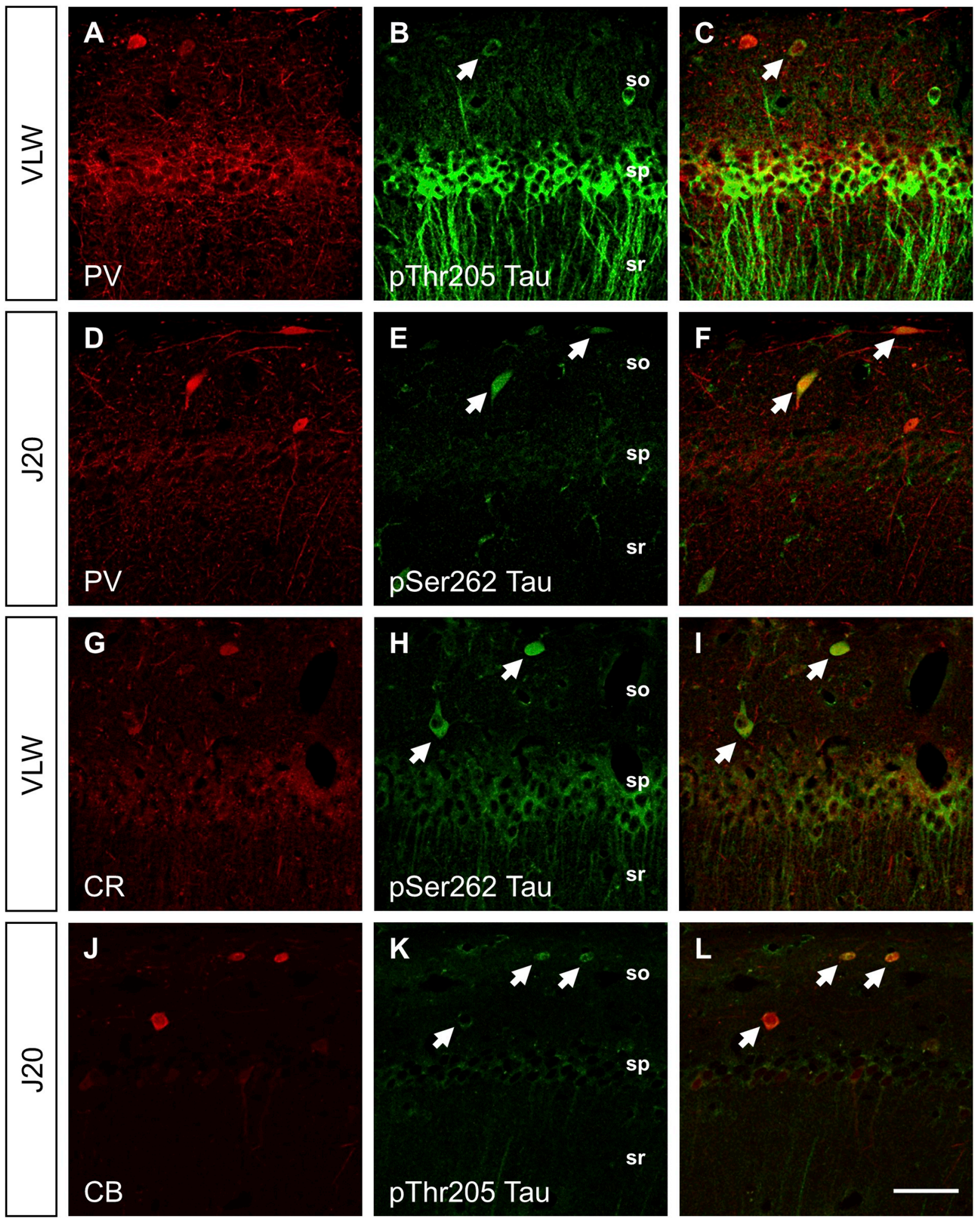

Fig. 9. VLW and J20 mice accumulate pSer262 and pThr205 Tau in PV-, CR- and CB-positive hippocampal interneurons. Double immunofluorescent detection of pSer262 or pThr205 Tau and interneuron markers PV, CR and CB in hippocampal sections from 8 mo VLW and J20 mice. (A-C and J-L) PV-, CR- and CB-positive hippocampal interneurons (red) accumulate Tau phosphorylated at residue Thr205 (green). Colocalization of pThr205 Tau with PV- (arrows in C) and CB-positive (arrows in L) interneurons. (D-I) PV-, CR- and CB-positive hippocampal interneurons (red) accumulate Tau phosphorylated at residue Ser262 (green). Colocalization of pSer262 Tau with PV- (arrows in F) and CR-positive (arrows in I) interneurons. Abbreviations: CB, Calbindin; CR, Calretinin; PV, Parvalbumin; so, stratum oriens; sp., stratum pyramidale; sr, stratum radiatum. Scale bar: $50 \mu \mathrm{m}$. (For interpretation of the references to colour in this figure legend, the reader is referred to the web version of this article.) 


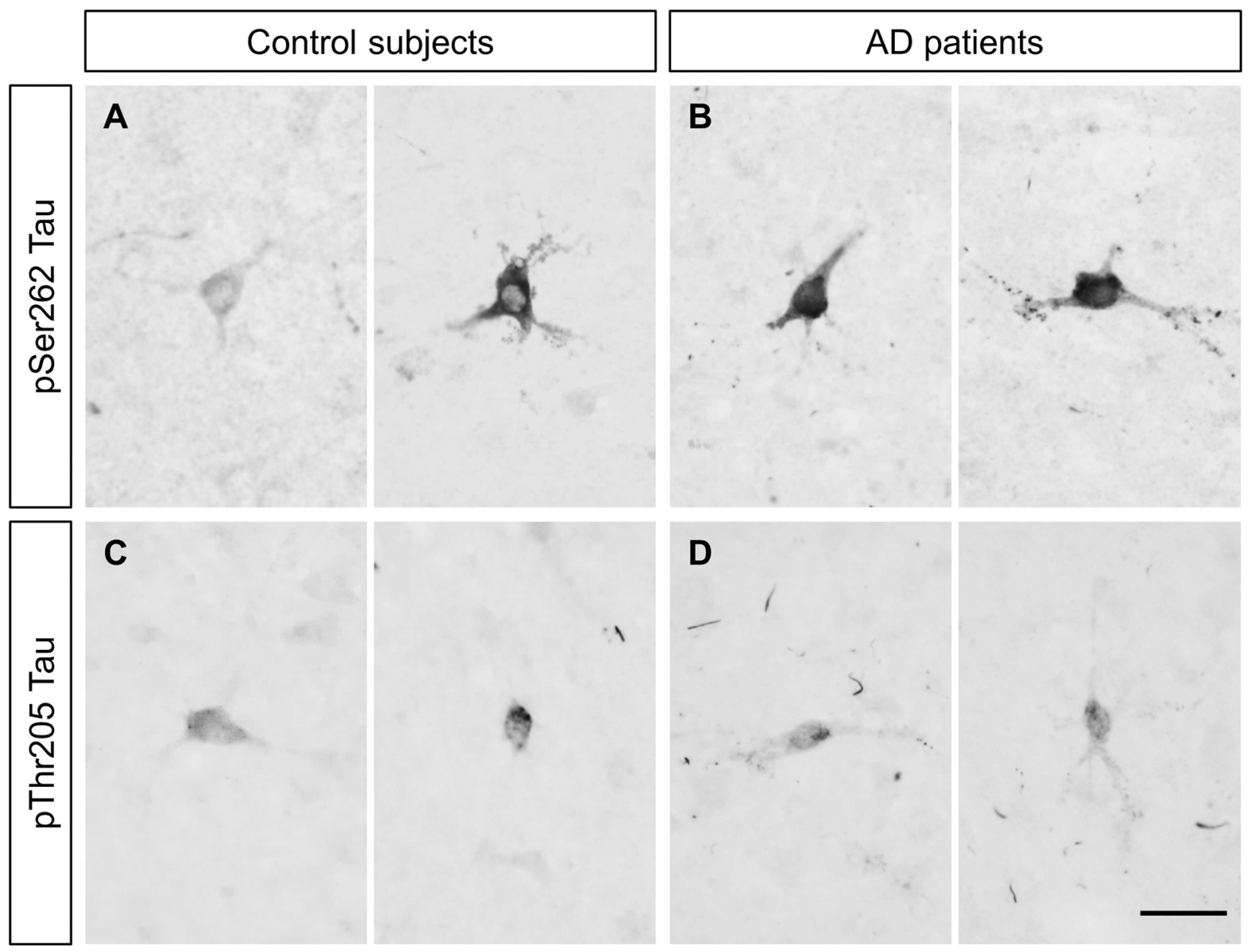

Fig. 10. pSer262 and pThr205 Tau accumulate in the soma of hippocampal interneurons in non-pathological and AD human subjects. Immunodetection of pSer262 or pThr205 Tau in the sr and slm in hippocampal sections from non-pathological and AD human subjects. (A and C) The soma of interneurons in non-pathological hippocampi accumulate pSer262 (A) and pThr205 (C) Tau. (B and D) The soma of hippocampal interneurons of AD patients accumulate pSer262 (B) and pThr205 (D) Tau. Scale bar: $50 \mu \mathrm{m}$.

that the former does not suppress the latter.

Our present data demonstrate that hTau expressed in pyramidal cells in VLW mice induces the phosphorylation of murine Tau at residue Thr231 in PV-positive interneurons. Therefore, we cannot discard the possibility that hyperphosphorylated hTau accumulated in the pyramidal cells of VLW mice represses the phosphorylation of murine Tau at residue Thr205 in hippocampal interneurons, thereby reducing the density of pThr205 Tau-positive interneurons.

In addition, many Tau residues, such as Thr205, are dependent on Glycogen Synthase Kinase 3 (GSK3) (Guo et al., 2017), a kinase that requires the previous (primed) phosphorylation of other Ser/Thr sites on its substrates, following a certain pattern, to exert its function (Medina et al., 2011; Sutherland, 2011). Hence, it cannot be discarded that VLW mice, a model of Tau hyperphosphorylation, show altered priming patterns of Tau phosphorylation, thus impeding GSK3 from correctly phosphorylating Tau at residue Thr205.

In contrast to the results obtained in VLW mice, J20 animals showed a significant increase in the density of cells accumulating pThr205 Tau in the CA1 so and DG with respect to WT mice.

$A \beta$ induces Tau hyperphosphorylation (Bolmont et al., 2007; Götz et al., 2001; Stancu et al., 2014). Our data indicate that the regions that show an increase in the number of cells accumulating pThr205 Tau correlate with those that display a higher $A \beta$ plaque load, thereby suggesting an inductive effect of $A \beta$ in the phosphorylation of Tau at residue Thr205. Thus, these data imply that the increase in the density of hippocampal interneurons accumulating pThr205 Tau in J20 mice could be a consequence of an inductive effect of $A \beta$ on Tau phosphorylation. It has recently been described that the specific phosphorylation of Tau at residue Thr205 inhibits A $\beta$ neurotoxicity (Ittner et al., 2016). This observation contrasts with the current view that Tau phosphorylation downstream of $A \beta$ toxicity is a pathological response. Thus, given that GABAergic hippocampal neurons appear to be resistant to neurotoxicity in AD (Canas et al., 2014; Mitew et al., 2013; Reinikainen et al., 1988; Rissman et al., 2007), our data showing an inductive effect of $A \beta$ on Tau phosphorylation at residue Thr205 in hippocampal interneurons could reflect a reaction in hippocampal interneurons to protect themselves from neurotoxicity. 4.4. The soma of some human hippocampal interneurons accumulate
pSer262 and pThr205 Tau in control subjects and AD patients

After observing that pSer262 and pThr205 Tau are present in hippocampal interneurons in physiological conditions, and that the number of cells accumulating pThr205 Tau increases in the presence of $A \beta$, we analyzed human hippocampal interneurons.

Our data show that human control and AD samples show few neurons accumulating pSer262 and pThr205 Tau in their soma in the sr and so. Despite the limited number of human samples analyzed, the location and morphology of pSer262 and pThr205 Tau-positive human neurons seem to correspond to hippocampal interneurons. Therefore, these results suggest that human hippocampal interneurons accumulate pSer262 and pThr205 Tau in control and pathological conditions. Thus, the presence of pSer262 and pThr205 Tau in the soma of interneurons in murine hippocampi is also detected in control and pathological 
human samples.

Our results reveal a differential pattern of phosphorylation and distribution of P-Tau in hippocampal interneurons and mossy cells. The data suggest that Tau protein acts differently in these neuronal populations, developing yet unknown additional functions in the soma. In addition, the presence of $\mathrm{P}$-Tau and $\mathrm{A} \beta$ influences the accumulation of pThr205 Tau in hippocampal interneurons, thereby supporting the notion that pThr205 Tau probably protects against $A \beta$ in $A D$.

Recently, various therapeutic approaches to $\mathrm{AD}$ have attempted to decrease the P-Tau as a strategy to prevent A $\beta$ toxicity (Medina, 2018; Pedersen and Sigurdsson, 2015). Our present data point to a physiological role of pSer262 and pThr205 Tau in the soma of hippocampal interneurons and that these phosphorylations are modulated by the presence of $A \beta$. Thus, our results evidence that caution must be taken when pharmacological modulation of Tau phosphorylation is proposed as a treatment for AD. A deeper understanding of the dynamics of Tau phosphorylation on the distinct hippocampal neuronal types may contribute to the design of new therapies for AD and other tauopathies. In this context, research into the behavior of Tau in hippocampal interneurons may broaden current knowledge of Tau function and impairment, and may also help to determine the potential of interneurons as a therapeutic target to halt the cognitive impairment associated with AD.

Supplementary data to this article can be found online at https:// doi.org/10.1016/j.nbd.2018.12.006.

\section{Disclosure statement} close.

The authors have no actual or potential conflicts of interest to dis-

\section{Acknowledgements}

The authors thank the personnel of the Advanced Optical Microscopy Facility at the Scientific and Technological Centers of the University of Barcelona for support, and the personnel of the Histopathology Facility of the Institute for Research in Biomedicine for assistance.

This work was supported by funds from FEDER/Ministerio de Ciencia, Innovación y Universidades, Agencia Estatal de Investigación/ SAF2016-76340-R to E.S., and by a FPU grant from the Ministry of Education, Culture and Sport (FPU2016-07395) awarded to E.D.

\section{References}

Amniai, L., Barbier, P., Sillen, A., Wieruszeski, J.-M., Peyrot, V., Lippens, G., Landrieu, I., 2009. Alzheimer disease specific phosphoepitopes of Tau interfere with assembly of tubulin but not binding to microtubules. FASEB J. 23, 1146-1152. https://doi.org/ 10.1096/fj.08-121590.

Ando, K., Maruko-Otake, A., Ohtake, Y., Hayashishita, M., Sekiya, M., Iijima, K.M., 2016. Stabilization of microtubule-unbound Tau via Tau phosphorylation at Ser262/356 by Par-1/MARK contributes to augmentation of AD-related phosphorylation and A 342 induced Tau toxicity. PLoS Genet. 12https://doi.org/10.1371/journal.pgen.1005917. e1005917.

Avila, J., 2009. The Tau code. Front. Aging Neurosci. 1, 1. https://doi.org/10.3389/ neuro.24.001.2009.

Avila, J., Lucas, J., Perez, M., Hernandez, F., 2004. Role of Tau protein in both physiological and pathological conditions. Physiol. Rev. 2, 361-384.

Ballatore, C., Lee, V.M.-Y.M.-Y., Trojanowski, J.Q., 2007. Tau-mediated neurodegeneration in Alzheimer's disease and related disorders. Nat. Rev. Neurosci. 8, 663-672. https://doi.org/10.1038/nrn2194.

Binder, L.I., Frankfurter, A., Rebhun, L.I., 1985. The distribution of Tau in the mammalian central nervous system. J. Cell Biol. 101, 1371-1378. https://doi.org/10.1083/jcb. 101.4.1371.

Bloom, G.S., 2014. Amyloid- $\beta$ and Tau: the trigger and bullet in Alzheimer disease pathogenesis. JAMA Neurol. 71, 505-508. https://doi.org/10.1001/jamaneurol.2013. 5847.

Bolmont, T., Clavaguera, F., Meyer-Luehmann, M., Herzig, M.C., Radde, R., Staufenbiel, M., Lewis, J., Hutton, M., Tolnay, M., Jucker, M., 2007. Induction of Tau pathology by intracerebral infusion of amyloid- $\beta$-containing brain extract and by amyloid- $\beta$ deposition in APP $\times$ Tau transgenic mice. Am. J. Pathol. 171, 2012-2020. https:// doi.org/10.2353/ajpath.2007.070403.

Braak, H., Thal, D.R., Ghebremedhin, E., Del Tredici, K., 2011. Stages of the pathologic process in Alzheimer disease: age categories from 1 to 100 years. J. Neuropathol. Exp. Neurol. 70, 960-969. https://doi.org/10.1097/NEN.0b013e318232a379.

Busche, M.A., Kekuš, M., Adelsberger, H., Noda, T., Förstl, H., Nelken, I., Konnerth, A., 2015. Rescue of long-range circuit dysfunction in Alzheimer's disease models. Nat. Neurosci. 18, 1623-1630. https://doi.org/10.1038/nn.4137.

Canas, P.M., Simões, A.P., Rodrigues, R.J., Cunha, R.A., 2014. Predominant loss of glutamatergic terminal markers in a $\beta$-amyloid peptide model of Alzheimer's disease. Neuropharmacology 76, 51-56. https://doi.org/10.1016/J.NEUROPHARM.2013.08. 026.

Cho, J., Johnson, G.V.W., 2004. Primed phosphorylation of Tau at Thr231 by glycogen synthase kinase $3 \mathrm{~b}$ (GSK3b) plays a critical role in regulating Tau's ability to bind and stabilize microtubules. J. Neurosci. 88, 349-358. https://doi.org/10.1111/j.14714159.2004.02155.x.

Clavaguera, F., Bolmont, T., Crowther, R.A., Abramowski, D., Frank, S., Probst, A., Fraser, G., Stalder, A.K., Beibel, M., Staufenbiel, M., Jucker, M., Goedert, M., Tolnay, M., 2009. Transmission and spreading of tauopathy in transgenic mouse brain. Nat. Cell Biol. 11, 909-913. https://doi.org/10.1038/ncb1901.

Drewes, G., Trinczek, B., Illenberger, S., Biernat, J., Schmitt-Ulms, G., Meyer, H.E., Mandelkow, E.-M., Mandelkow, E., 1995. Microtubule-associated protein/microtubule affinity-regulating kinase (p110 mark). J. Biol. Chem. 270, 7679-7688. https://doi.org/10.1074/jbc.270.13.7679.

Drubin, D.G., Kirschner, M.W., 1986. Tau protein function in living cells. J. Cell Biol. 103, 2739-2746.

Flach, K., Hilbrich, I., Schiffmann, A., Gärtner, U., Krüger, M., Leonhardt, M., Waschipky, H., Wick, L., Arendt, T., Holzer, M., 2012. Tau oligomers impair artificial membrane integrity and cellular viability. J. Biol. Chem. 287, 43223-43233. https://doi.org/10. 1074/jbc.M112.396176.

Forner, S., Baglietto-Vargas, D., Martini, A.C., Trujillo-Estrada, L., LaFerla, F.M., 2017. Synaptic impairment in Alzheimer's disease: a dysregulated symphony. Trends Neurosci. https://doi.org/10.1016/j.tins.2017.04.002.

Frandemiche, M.L., De Seranno, S., Rush, T., Borel, E., Elie, A., Arnal, I., Lante, F., Buisson, A., 2014. Activity-dependent tau protein translocation to excitatory synapse is disrupted by exposure to amyloid-beta oligomers. J. Neurosci. 34, 6084-6097. https://doi.org/10.1523/JNEUROSCI.4261-13.2014.

Freund, T.F., Buzsaki, G., 1996. Interneurons of the hippocampus. Hippocampus 6, $347-470$.

Furcila, D., DeFelipe, J., Alonso-Nanclares, L., 2018. A study of amyloid- $\beta$ and phosphotau in plaques and neurons in the hippocampus of alzheimer's disease patients. J. Alzheimers Dis. 64, 417-435. https://doi.org/10.3233/JAD-180173.

Goedert, M., Jakes, R., Crowther, R. a, Cohen, P., Vanmechelen, E., Vandermeeren, M., Cras, P., 1994. Epitope mapping of monoclonal antibodies to the paired helical filaments of Alzheimer's disease: identification of phosphorylation sites in tau protein. Biochem. J. 301 (Pt 3), 871-877.

Götz, J., Probst, A., Spillantini, M.G., Schäfer, T., Jakes, R., Bürki, K., Goedert, M., 1995. Somatodendritic localization and hyperphosphorylation of tau protein in transgenic mice expressing the longest human brain tau isoform. EMBO J. 14, 1304-1313.

Götz, J., Chen, F., van Dorpe, J., Nitsch, R.M., 2001. Formation of neurofibrillary tangles in P3011 tau transgenic mice induced by Abeta 42 fibrils. Science 293, 1491-1495. https://doi.org/10.1126/science.1062097.

Guo, T., Noble, W., Hanger, D.P., 2017. Roles of tau protein in health and disease. Acta Neuropathol. 133, 665-704. https://doi.org/10.1007/s00401-017-1707-9.

Haass, C., Selkoe, D.J., 2007. Soluble protein oligomers in neurodegeneration: lessons from the Alzheimer's amyloid $\beta$-peptide. Nat. Rev. Mol. Cell Biol. 8, 101-112. https://doi.org/10.1038/nrm2101.

Hanger, D.P., Byers, H.L., Wray, S., Leung, K.Y., Saxton, M.J., Seereeram, A., Reynolds, C.H., Ward, M.A., Anderton, B.H., 2007. Novel phosphorylation sites in Tau from Alzheimer brain support a role for casein kinase 1 in disease pathogenesis. J. Biol. Chem. 282, 23645-23654. https://doi.org/10.1074/jbc.M703269200.

Hernández, F., Avila, J., 2007. Tauopathies. Cell. Mol. Life Sci. 64, 2219-2233. https:// doi.org/10.1007/s00018-007-7220-x.

Hoover, B.R., Reed, M.N., Su, J., Penrod, R.D., Kotilinek, L.A., Grant, M.K., Pitstick, R., Carlson, G.A., Lanier, L.M., Yuan, L.L., Ashe, K.H., Liao, D., 2010. Tau mislocalization to dendritic spines mediates synaptic dysfunction independently of neurodegeneration. Neuron 68, 1067-1081. https://doi.org/10.1016/j.neuron.2010.11.030.

Hutton, M., Lendon, C.L., Rizzu, P., Baker, M., Froelich, S., Houlden, H., Pickering-Brown, S., Chakraverty, S., Isaacs, A., Grover, A., Hackett, J., Adamson, J., Lincoln, S., Dickson, D., Davies, P., Petersen, R.C., Stevens, M., de Graaff, E., Wauters, E., van Baren, J., Hillebrand, M., Joosse, M., Kwon, J.M., Nowotny, P., Che, L.K., Norton, J., Morris, J.C., Reed, L.A., Trojanowski, J., Basun, H., Lannfelt, L., Neystat, M., Fahn, S. Dark, F., Tannenberg, T., Dodd, P.R., Hayward, N., Kwok, J.B.J., Schofield, P.R., Andreadis, A., Snowden, J., Craufurd, D., Neary, D., Owen, F., Oostra, B.A., Hardy, J., Goate, A., van Swieten, J., Mann, D., Lynch, T., Heutink, P., 1998. Association of missense and 5 -splice-site mutations in tau with the inherited dementia FTDP-17 in tau with the inherited dementia FTDP-17. Nature 393, 702-705. https://doi.org/10. $1038 / 31508$.

Iqbal, K., Liu, F., Gong, C.X., 2016. Tau and neurodegenerative disease: The story so far Nat. Rev. Neurol. https://doi.org/10.1038/nrneurol.2015.225.

Ittner, L.M., Götz, J., 2011. Amyloid- $\beta$ and tau — a toxic pas de deux in Alzheimer's disease. Nat. Rev. Neurosci. 12, 67-72. https://doi.org/10.1038/nrn2967.

Ittner, L.M., Ke, Y.D., Delerue, F., Bi, M., Gladbach, A., van Eersel, J., Wölfing, H., Chieng, B.C., Christie, M.J., Napier, I.A., Eckert, A., Staufenbiel, M., Hardeman, E., Götz, J., 2010. Dendritic function of tau mediates amyloid- $\beta$ toxicity in alzheimer's disease mouse models. Cell 142, 387-397. https://doi.org/10.1016/j.cell.2010.06.036.

Ittner, A., Chua, S.W., Bertz, J., Volkerling, A., van der Hoven, J., Gladbach, A., Przybyla, M., Bi, M., van Hummel, A., Stevens, C.H., Ippati, S., Suh, L.S., Macmillan, A., Sutherland, G., Kril, J.J., Silva, A.P.G., Mackay, J.P., Poljak, A., Delerue, F., Ke, Y.D., 
Ittner, L.M., 2016. Site-specific phosphorylation of tau inhibits amyloid- $\beta$ toxicity in Alzheimer's mice. Science 354 (80-.).

Jin, M., Shepardson, N., Yang, T., Chen, G., Walsh, D., Selkoe, D.J., 2011. Soluble amyloid beta-protein dimers isolated from Alzheimer cortex directly induce Tau hyperphosphorylation and neuritic degeneration. Proc. Natl. Acad. Sci. U. S. A. 108, 5819-5824. https://doi.org/10.1073/pnas.1017033108.

Khan, S.S., Bloom, G.S., 2016. Tau: the center of a signaling nexus in alzheimer's disease. Front. Neurosci. 10, 31. https://doi.org/10.3389/fnins.2016.00031.

Kidd, M., 1963. Paired helical filaments in electron microscopy of Alzheimer's disease. Nature 197, 192.

Kopke, E., Tung, Y.C., Shaikh, S., Del Alonso, C.A., Iqbal, K., Grundke-Iqbal, I., 1993. Microtubule-associated protein tau. Abnormal phosphorylation of a non- paired helical filament pool in Alzheimer disease. J. Biol. Chem. 268, 24374-24384. https:// doi.org/10.1016/j.bbrc.2011.11.056.

Lee, V.M.-Y., Goedert, M., Trojanowski, J.Q., 2001. Neurodegenerative Tauopathies. Annu. Rev. Neurosci. 24, 1121-1159. https://doi.org/10.1146/annurev.neuro.24.1 1121.

Lim, F., Hernández, F., Lucas, J.J., Gómez-Ramos, P., Morán, M. a, Avila, J., 2001. FTDP17 mutations in tau transgenic mice provoke lysosomal abnormalities and Tau filaments in forebrain. Mol. Cell. Neurosci. 18, 702-714. https://doi.org/10.1006/mcne. 2001.1051.

Matyas, F., Freund, T.F., Gulyas, A.I., 2004. Immunocytochemically defined interneuron populations in the hippocampus of mouse strains used in transgenic technology. Hippocampus 14, 460-481.

Medina, M., 2018. An overview on the clinical development of tau-based therapeutics. Int. J. Mol. Sci. 19, 1160. https://doi.org/10.3390/ijms19041160.

Medina, M., Garrido, J.J., Wandosell, F.G., 2011. Modulation of GSK-3 as a Therapeutic Strategy on Tau Pathologies. vol. 4. pp. 1-10. https://doi.org/10.3389/fnmol.2011. 00024 .

Medina, M., Hernández, F., Avila, J., 2016. New features about tau function and dysfunction. Biomolecules 6. https://doi.org/10.3390/biom6020021.

Mitew, S., Kirkcaldie, M.T.K., Dickson, T.C., Vickers, J.C., 2013. Altered synapses and gliotransmission in Alzheimer's disease and AD model mice. Neurobiol. Aging 34, 2341-2351. https://doi.org/10.1016/J.NEUROBIOLAGING.2013.04.010.

Morishima-Kawashima, M., Hasegawa, M., Takio, K., Suzuki, M., Yoshida, H., Titani, K., Ihara, Y., 1995. Proline-directed and non-proline-directed phosphorylation of PHFtau. J. Biol. Chem. https://doi.org/10.1074/jbc.270.2.823.

Mucke, L., Masliah, E., Yu, G.Q., Mallory, M., Rockenstein, E.M., Tatsuno, G., Hu, K., Kholodenko, D., Johnson-Wood, K., McConlogue, L., 2000. High-level neuronal expression of abeta 1-42 in wild-type human amyloid protein precursor transgenic mice: synaptotoxicity without plaque formation. J. Neurosci. 20, 4050-4058.

Palop, J.J., Mucke, L., 2010. Amyloid-[beta]-induced neuronal dysfunction in Alzheimer's disease: from synapses toward neural networks. Nat. Neurosci. 13, 812-818.

Palop, J.J., Mucke, L., 2016. Network abnormalities and interneuron dysfunction in Alzheimer disease. Nat. Rev. Neurosci. 17, 777-792. https://doi.org/10.1038/nrn. 2016.141.

Papasozomenos, S.C., Binder, L.I., 1987. Phosphorylation determines two distinct species of tau in the central nervous system. Cell Motil. Cytoskeleton 8, 210-226. https://doi. org $/ 10.1002 / \mathrm{cm} .970080303$.

Pedersen, J.T., Sigurdsson, E.M., 2015. Tau immunotherapy for Alzheimer's disease. Trends Mol. Med. 21, 394-402. https://doi.org/10.1016/j-molmed 2015.03.003.

Polanco, J.C., Scicluna, B.J., Hill, A.F., Götz, J., 2016. Extracellular Vesicles Isolated from the Brains of rTg4510 Mice Seed Tau Protein Aggregation in a Threshold-dependent Manner. J. Biol. Chem. 291, 12445-12466. https://doi.org/10.1074/jbc.M115. 709485.

Reinikainen, K.J., Paljärvi, L., Huuskonen, M., Soininen, H., Laakso, M., Riekkinen, P.J., 1988. A post-mortem study of noradrenergic, serotonergic and GABAergic neurons in Alzheimer's disease. J. Neurol. Sci. 84, 101-116. https://doi.org/10.1016/0022510X(88)90179-7.

Rissman, R.A., De Blas, A.L., Armstrong, D.M., 2007. GABA ${ }_{\mathrm{A}}$ receptors in aging and Alzheimer's disease. J. Neurochem. 103, 1285-1292. https://doi.org/10.1111/j. 1471-4159.2007.04832.x.

Roberson, E.D., Scearce-Levie, K., Palop, J.J., Yan, F., Cheng, I.H., Wu, T., Gerstein, H., Yu, G.-Q.Q., Mucke, L., 2007. Reducing endogenous tau ameliorates amyloid betainduced deficits in an Alzheimer's disease mouse model. Science 316, 750-754. https://doi.org/10.1126/science.1141736. (80-.).

Roberson, E.D., Halabisky, B., Yoo, J.W., Yao, J., Chin, J., Yan, F., Wu, T., Hamto, P., Devidze, N., Yu, G.-Q., Palop, J.J., Noebels, J.L., Mucke, L., 2011. Amyloid- $\beta /$ Fyninduced synaptic, network, and cognitive impairments depend on tau levels in multiple mouse models of Alzheimer's disease. J. Neurosci. 31, 700-711. https://doi. org/10.1523/JNEUROSCI.4152-10.2011.

SantaCruz, K., Lewis, J., Spires, T., Paulson, J., Kotilinek, L., Ingelsson, M., Guimaraes, A., DeTure, M., Ramsden, M., McGowan, E., Forster, C., Yue, M., Orne, J., Janus, C. Mariash, A., Kuskowski, M., Hyman, B., Hutton, M., Ashe, K.H., 2005. Tau suppression in a neurodegenerative mouse model improves memory function. Science (80-.).
309, 476-481. https://doi.org/10.1126/science.1113694.

Schindelin, J., Arganda-Carreras, I., Frise, E., Kaynig, V., Longair, M., Pietzsch, T. Preibisch, S., Rueden, C., Saalfeld, S., Schmid, B., Tinevez, J.-Y., White, D.J., Hartenstein, V., Eliceiri, K., Tomancak, P., Cardona, A., 2012. Fiji: an open-source platform for biological-image analysis. Nat. Methods 9, 676-682. https://doi.org/10. 1038 /nmeth. 2019.

Schneider, A., Biernat, J., von Bergen, M., Mandelkow, E., Mandelkow, E.-M., 1999. Phosphorylation that detaches tau protein from microtubules (Ser262, Ser214) also protects it against aggregation into Alzheimer paired helical filaments. Biochemistry 38, 3549-3558. https://doi.org/10.1021/bi981874p.

Sengupta, A., Kabat, J., Novak, M., Wu, Q., Grundke-Iqbal, I., Iqbal, K., 1998. Phosphorylation of tau at both Thr 231 and Ser 262 is required for maximal inhibition of its binding to microtubules. Arch. Biochem. Biophys. 357, 299-309. https://doi.org/10.1006/abbi.1998.0813.

Šimić, G., Babić Leko, M., Wray, S., Harrington, C., Delalle, I., Jovanov-Milošević, N., Bažadona, D., Buée, L., de Silva, R., Di Giovanni, G., Wischik, C., Hof, P.R., 2016. Tau protein hyperphosphorylation and aggregation in alzheimer's disease and other tauopathies, and possible neuroprotective strategies. Biomolecules. https://doi.org/ 10.3390/biom6010006.

Soler, H., Dorca-Arévalo, J., González, M., Rubio, S.E., Ávila, J., Soriano, E., Pascual, M. Avila, J., Soriano, E., Pascual, M., 2017. The GABAergic septohippocampal connection is impaired in a mouse model of tauopathy. Neurobiol. Aging 49, 40-51. https:// doi.org/10.1016/j.neurobiolaging.2016.09.006.

Sotiropoulos, I., Galas, M.-C., Silva, J.M., Skoulakis, E., Wegmann, S., Maina, M.B., Blum, D., Sayas, C.L., Mandelkow, E.-M., Mandelkow, E., Spillantini, M.G., Sousa, N., Avila, J., Medina, M., Mudher, A., Buee, L., 2017. Atypical, non-standard functions of the microtubule associated Tau protein. Acta Neuropathol. Commun. 5, 91. https://doi. org/10.1186/s40478-017-0489-6.

Stancu, I., Vasconcelos, B., Terwel, D., Dewachter, I., 2014. Models of $\beta$-amyloid Induced Tau-pathology: The Long and "Folded" Road to Understand the Mechanism. pp. 1-14.

Sultan, A., Nesslany, F., Violet, M., Bégard, S., Loyens, A., Talahari, S., Mansuroglu, Z., Marzin, D., Sergeant, N., Humez, S., Colin, M., Bonnefoy, E., Buée, L., Galas, M.-C., 2011. Nuclear Tau, a key player in neuronal DNA protection. J. Biol. Chem. 286, 4566-4575. https://doi.org/10.1074/jbc.M110.199976.

Sutherland, C., 2011. What are the bona fide GSK3 substrates? Int. J. Alzheimers Dis. 1-23. https://doi.org/10.4061/2011/505607.

Thies, E., Mandelkow, E.-M., 2007. Missorting of tau in neurons causes degeneration of synapses that can be rescued by the kinase MARK2/Par-1. J. Neurosci. 27, 2896-2907. https://doi.org/10.1523/JNEUROSCI.4674-06.2007.

Tian, H., Davidowitz, E., Lopez, P., Emadi, S., Moe, J., Sierks, M., 2013. Trimeric tau is toxic to human neuronal cells at low nanomolar concentrations. Int. J. Cell Biol. 2013, 1-9. https://doi.org/10.1155/2013/260787.

Verret, L., Mann, E.O., Hang, G.B., Barth, A.M.I., Cobos, I., Ho, K., Devidze, N., Masliah, E., Kreitzer, A.C., Mody, I., Mucke, L., Palop, J.J., 2012. Inhibitory interneuron deficit links altered network activity and cognitive dysfunction in Alzheimer model. Cell 149, 708-721. https://doi.org/10.1016/j.cell.2012.02.046.

Villette, V., Dutar, P., 2016. GABAergic microcircuits in Alzheimer's disease models. Curr. Alzheimer Res. 13, 1. https://doi.org/10.2174/1567205013666160819125757.

Violet, M., Delattre, L., Tardivel, M., Sultan, A., Chauderlier, A., Caillierez, R., Talahari, S., Nesslany, F., Lefebvre, B., Bonnefoy, E., Buée, L., Galas, M.-C., 2014. A major role for Tau in neuronal DNA and RNA protection in vivo under physiological and hyperthermic conditions. Front. Cell. Neurosci. 8, 1-11. https://doi.org/10.3389/fncel. 2014.00084.

Wang, Y., Mandelkow, E., 2016. Tau in physiology and pathology. Nat. Rev. Neurosci. 17, 5-21. https://doi.org/10.1038/nrn.2015.1.

Wang, Y., Balaji, V., Kaniyappan, S., Krüger, L., Irsen, S., Tepper, K., Chandupatla, R., Maetzler, W., Schneider, A., Mandelkow, E., Mandelkow, E.M., 2017. The release and trans-synaptic transmission of Tau via exosomes. Mol. Neurodegener. 12. https://doi. org/10.1186/s13024-016-0143-y.

Weingarten, M.D., Lockwood, A.H., Hwo, S.Y., Kirschner, M.W., 1975. A protein factor essential for microtubule assembly. Proc. Natl. Acad. Sci. U. S. A. 72, 1858-1862. https://doi.org/10.1073/pnas.72.5.1858.

Xia, D., Li, C., Götz, J., 2015. Pseudophosphorylation of Tau at distinct epitopes or the presence of the P301L mutation targets the microtubule-associated protein Tau to dendritic spines. Biochim. Biophys. Acta 1852, 913-924. https://doi.org/10.1016/j. bbadis. 2014.12.017.

Yoshiyama, Y., Higuchi, M., Zhang, B., Huang, S.M., Iwata, N., Saido, T.C.C., Maeda, J., Suhara, T., Trojanowski, J.Q., Lee, V.M.-Y., 2007. Synapse Loss and microglial activation precede tangles in a P301S tauopathy mouse model. Neuron 53, 337-351. https://doi.org/10.1016/j.neuron.2007.01.010.

Zempel, H., Luedtke, J., Kumar, Y., Biernat, J., Dawson, H., Mandelkow, E., Mandelkow, E.-M., 2013. Amyloid- $\beta$ oligomers induce synaptic damage via Tau-dependent microtubule severing by TTLL6 and spastin. EMBO J. 32, 2920-2937. https://doi.org/ 10.1038/emboj.2013.207. 